\title{
Neuroadaptive changes and behavioral effects after a sensitization regime of MDPV
}

\author{
Duart-Castells, L. ${ }^{1}$, López-Arnau, R. ${ }^{1}$; Buenrostro-Jáuregui, M. ${ }^{1,2}$; Muñoz-Villegas P. ${ }^{1}$; \\ Valverde, O. ${ }^{3}$, Camarasa, J. ${ }^{1}$, Pubill, D. ${ }^{1^{*}}$, Escubedo, E. ${ }^{1 * \varpi}$ \\ ${ }^{1}$ Department of Pharmacology and Therapeutic Chemistry, Pharmacology Section and Institute \\ of Biomedicine (IBUB), Faculty of Pharmacy, University of Barcelona, Barcelona, Spain. \\ ${ }^{2}$ Neuroscience Laboratory, Department of Psychology, Universidad Iberoamericana, Mexico \\ City, Mexico. \\ ${ }^{3}$ Neurobiology of Behavior Research Group (GReNeC-NeuroBio), Department of Experimental \\ and Health Sciences, Universitat Pompeu Fabra, Barcelona, Spain. \\ * Contributed equally to this work. \\ $\bowtie$ Corresponding author: \\ Elena Escubedo \\ Department of Pharmacology, Toxicology and Therapeutic Chemistry, Faculty of Pharmacy, \\ University of Barcelona. Avda. Joan XXIII 27-31. Barcelona 08028, Spain. \\ Tel: +34-934024531 \\ E-mail: eescubedo@ub.edu
}

Running title: Effects induced by a sensitization regime of MDPV

\begin{abstract}
3,4-methylenedioxypyrovalerone (MDPV) is a synthetic cathinone with cocaine-like properties. In a previous work, we exposed adolescent mice to MDPV, finding sensitization to cocaine effects, and a higher vulnerability to cocaine abuse in adulthood. Here we sought to determine if such MDPV schedule induces additional behavioral-neuronal changes that could explain such results.
\end{abstract}

After MDPV treatment (1.5 mg. $\mathrm{kg}^{-1}$, twice daily, 7 days), mice were behaviorally tested. Also, we investigated protein changes in various brain regions

MDPV induced aggressiveness and anxiety, but also contributed to a faster habituation to the open field. This feature co-occurred with an induction of $\triangle \mathrm{FosB}$ in the orbitofrontal cortex that was higher than its expression in the ventral striatum.

Early after treatment, D2R:D1R ratio pointed to a preponderance of D1R but, upon withdrawal, the ratio recovered. Increased expression of Arc, CDK5 and TH, and decrease in DAT protein levels persisted longer after withdrawal, pointing to a neuroplastic lasting effect similar to that involved in cocaine addiction. The implication of the hyperdopaminergic condition in the MDPV-induced aggressiveness cannot be ruled out. We also found an initial oxidative effect of MDPV, without glial activation. Moreover, although initially the dopaminergic signal induced by MDPV resulted in increased $\triangle \mathrm{FosB}$, we did not observe any change in NFkB or GluA2 expression.

Finally, the changes observed after MDPV treatment could not be explained according to the autoregulatory loop between $\triangle \mathrm{FosB}$ and the epigenetic repressor G9a described for cocaine. This provides new knowledge about the neuroadaptive changes involved in the vulnerability to psychostimulant addiction. 


\section{HIGHLIGHTS}

- Adolescent mice treated with MDPV were tested at early and late withdrawal

- MDPV group showed increased entries to center in the open field test

- The rise in cortical $\triangle \mathrm{FosB}$ by MDPV correlates with this risky behavior

- $\quad$ MDPV induced lasting overexpression of Arc, CDK5 and changes in dopaminergic status

- $\quad 24 \mathrm{~h}$ after treatment, oxidative markers and $G 9 a \mathrm{~N}$-methyltransferase were increased

KEYWORDS: MDPV; Adolescent mice; Sensitization, Cocaine, Transcription factors, Dopamine

\section{NON-STANDARD ABBREVIATIONS:}

4-HNE, 4-hydroxy-2-nonenal;

ARC, activity-regulated cytoskeleton-associated protein;

$\mathrm{BS}^{3}$, bis(sulfosuccinimidyl)suberate;

CDK5, cyclin-dependent kinase-5;

DA, dopamine;

DAT, Dopamine transporter (DAT);

DR1, dopamine 1 receptor;

DR2, dopamine 2 receptor;

DS, dorsal striatum;

EPM, elevated plus maze;

G9a, G9a methyltransferase;

GFAP, glial fibrillary acidic protein;

GluA2, AMPA glutamate receptor A2 subunit;

MDPV, 3,4-methylene-dioxy-pyrovalerone;

OF, open field;

OFC, orbitofrontal cortex;

PVDF, polyvinilidene fluoride sheets;

RIT, resident intruder test;

VS, ventral striatum, including NAcc; 
W1, 1 day after the end of the treatment;

W2, 2 days after the end of the treatment;

W3, 3 days after the end of the treatment;

W21, 21 days after the end of the treatment, is the end of the withdrawal.

\section{FUNDING}

This study was supported by Ministerio de Economia y Competitividad (grant number SAF2016-75347-R, SAF2016-75966-R), and Plan Nacional sobre Drogas (\#2016I004). LDC received FPU grants from the Ministerio de Economía y Competitividad (15/02492). R. LópezArnau position was funded by an institutional program of the Universitat de Barcelona in collaboration with Obra Social de la Fundació Bancària La Caixa. JC, DP and EE belong to 2017SGR979, and OV to 2017SGR109 from the Generalitat de Catalunya.

\section{DECLARATION OF INTEREST: NONE}

\section{CHEMICAL COMPOUNDS STUDIED IN THIS ARTICLE:}

- 3,4-methylenedioxypyrovalerone (PubChem CID: 20111961)

- Cocaine (PubChem CID: 11302220)

\section{INTRODUCTION}

Synthetic cathinones (i.e. mephedrone, methylone and MDPV, etc) are used as substitutes for other stimulants such as amphetamines, cocaine or ecstasy. Among them, pyrrolidine derivatives such as 3,4-methylenedioxypyrovalerone (MDPV) are more lipophilic and more able to cross the blood-brain barrier. MDPV shows cocaine-like properties and selectively inhibits dopamine (DAT) and noradrenaline transporters, being 10- to 50-fold more potent than cocaine as a DAT blocker (Baumann et al., 2013; Simmler et al., 2013). Some authors found that MDPV has powerful rewarding and reinforcing effects relative to cocaine at one-tenth doses, suggesting that this drug has significant abuse risk based on its potency and subjectively positive effects (Aarde et al., 2013; Watterson et al., 2012).

Repeated administration of psychostimulants induces psychomotor sensitization in rodents. This phenomenon has been proposed as a model of an initial stage of psychostimulant addiction in humans and it contributes to drug craving (Kalivas and Stewart, 1991; Robinson and Berridge, 1993). In a previous work, after a twice-daily administration of a moderate dose of MDPV to adolescent mice during 7 days, we found a significant sensitization to cathinone locomotor effects. In the present work, we tested if repeated exposure to MDPV elicited a distinct behavior during withdrawal. With this purpose we evaluated anxiety, habituation and aggressiveness using the elevated plus maze (EPM), the open field (OF) and the resident intruder test (RIT) paradigms, respectively.

Cocaine exposure triggers complex adaptations in the brain that are mediated by dynamic patterns of gene expression, which are further translated into enduring changes (Schmidt et al., 
2013). The purpose of the present study was also to evaluate changes in specific neuronal biomarkers after a sensitization regime of MDPV that could explain such increase of cocaine effects. Also, this knowledge will lead us to a better understanding about the effects of chronic MDPV exposure and its neurotoxicological potential.

In the ventral striatum (VS), we mostly focused on $\triangle \mathrm{FosB}$ pathway, which is triggered by dopamine 1 receptor (DR1) and p-CREB signaling. We also studied related markers including cyclin-dependent kinase-5 (CDK5), GluA2, an AMPA glutamate receptor subunit, nuclear factor kappa $\mathrm{B}(\mathrm{NF \kappa B})$ and activity-regulated cytoskeleton-associated protein (Arc). To be activated, $\mathrm{CDK} 5$ has to associate with its regulatory subunit, p35, both regulated by $\triangle \mathrm{FosB}$ (McClung et al., 2004; Nikolic et al., 1996). The p35/CDK5 is a neuroplasticity mediator, which is required for neurite growth (Patrick et al., 1999). On the contrary, p25, a proteolytic fragment of p35, causes dysregulation of CDK5 kinase activity. Furthermore, the complex p25/CDK5 hyperphosphorylates tau, which reduces tau's ability to associate with microtubules (Kelz et al., 1999) when CDK5 is activated by $\mathrm{p} 35$, it takes part in physiological processes as neuroplasticity, while $\mathrm{CDK} 5 / \mathrm{p} 25$ and $\mathrm{Cdk} 5 / \mathrm{p} 29$ are related with neurotoxic and neurodegenerative processes. Arc is an early gene which is rapidly induced by cocaine. GluA2 is also a target gene of $\Delta \mathrm{FosB}$, but its expression is also under homeostatic regulation as well as its surface/intracellular ratio. (Boudreau et al., 2007). Finally, we also determined G9a a histone-lysine N-methyltransferase, because it is considered an important control mechanism for epigenetic regulation during the development of cocaine addiction state (Maze et al., 2010).

In the dorsal striatum (DS) we measured the expression of parameters related with dopaminergic neurotransmission. Repeated exposure to classical psychostimulants also induces various synaptic adaptations, many of them related to sensitization and neuroplastic processes including up- or down-regulation of DR1 (RRID:RGD_10412325) and DR2 (RRID:IMSR_RBRC02332), changes in subunits of G proteins, increased adenylyl cyclase activity and increased tyrosine hydroxylase enzyme (TH) activity or dopamine (DA) transport (Bibb et al., 2001). Accordingly TH, DAT, DR1 and DR2 levels, as well as lipid peroxidation were assessed following MDPV exposure. Lipid peroxidation is one of the major sources of free radical-mediated injury that directly damages membranes and generates a number of secondary products. Following lipid peroxidation, 4-hydroxy-2-nonenal (HNE) is one of the most abundant resulting products. Therefore, $4-\mathrm{HNE}$ is considered a robust marker of oxidative stress and a toxic compound for several cell types (Perluigi et al., 2012). Its assessment, jointly with that of GFAP, provided information about a putative neurotoxic effect of MDPV.

Some data indicate that the induction of $\triangle F$ FosB within the OFC plays a role in the deficit in impulse control mediated by cocaine (Winstanley et al., 2009). For this reason and in view of the results obtained in the $\mathrm{OF}$, we also assessed the induction of $\Delta \mathrm{FosB}$ in this cortical area.

\section{MATERIALS AND METHODS}

\subsection{Animals}

All animal care and experimental protocols in this study were approved by the Animal Ethics Committee of the University of Barcelona, under the supervision of the Autonomic Government of Catalonia, and are in accordance with the United States Public Health Service Guide for the Care and Use of Laboratory Animals and with European Community Council Directive (2010/63/EU for animal experiments). All efforts were made to minimize animal suffering and to reduce the number of animals used. Animal studies are reported in compliance with the 
ARRIVE guidelines. CD-1 mouse strain was selected for its optimal sensitivity to the reinforcing and psychostimulant effects of cocaine (McKerchar et al., 2005). Animals were housed six per cage (polycarbonate with wood-derived bedding) at $22 \pm 1{ }^{\circ} \mathrm{C}$ under a $12 \mathrm{~h}$ light/dark cycle with free access to food and drinking water. Male Swiss CD-1 mice (Charles River, Spain) at the beginning of periadolescence (PND 41-44) were used.

\subsection{Materials}

Pure racemic MDPV - $\mathrm{HCl}$ was synthesized and characterized in our laboratory as previously described (Novellas et al., 2005). Cocaine was provided by the Spanish National Institute of Toxicology. Both MDPV and cocaine solutions were prepared in $0.9 \% \mathrm{NaCl}$ (saline, $\mathrm{pH}=7.4$ ) immediately before administration.

The protease and phosphatase inhibitors cocktail was purchased from Abcam (Cambridge, UK). $\mathrm{BS}^{3}$ [bis(sulfosuccinimidyl)suberate] was from ThermoFisher Scientific (Rockford, USA) and $\left[{ }^{3} \mathrm{H}\right]$ WIN 35428 was from Perkin Elmer (Boston, USA). All the other reagents were of analytical grade and purchased from several commercial sources.

\subsection{Drug administration protocol and experimental design}

Mice were treated with MDPV (1.5 mg. $\mathrm{kg}^{-1}$, s.c.) or saline (5 ml-kg-1 s.c.), two doses in one day (4 $\mathrm{h}$ apart), for seven consecutive days, and housed in their cages until reaching adulthood (PND 69-72, 21 days). Behavioral tests including resident-intruder test (RIT), elevated plus maze (EPM) and the open field (OF) paradigms were performed during withdrawal as described below (Fig. 1A). Different lots of animals were used for biochemical and behavioral experiments. Doses of drugs and treatment schedules are based on our previous study (LópezArnau et al., 2017).

\subsection{Elevated plus maze (EPM)}

Either 48h (W2) or 21 days (W21) after treatment, the anxiety-related behavior was measured using the EPM paradigm. Briefly, the maze was elevated $42 \mathrm{~cm}$ above the ground and consisted of two open and two closed arms $(30 \times 6 \mathrm{~cm})$ which radiated from a central platform $(6 \times 6 \mathrm{~cm})$. Testing was conducted under low room lighting conditions (30 LUX). The mice were placed on the center, facing an open arm, an allowed to explore for $5 \mathrm{~min}$.-The behavior was recorded by a zenithal camera connected to a computerized tracking system (Smart 3.0 software, PanLab SL, Spain). The time spent in the center of the maze was discarded and the results are expressed as the total time spent in closed and open arms.

\subsection{Open field $(O F)$}

Either 3(W3) or 21 days (W21) after the end of the treatment, the same mice were evaluated in a circular open arena sized $100 \mathrm{~cm}$ in diameter. Previously, mice underwent two consecutive habituation sessions (10 min, days W1 and W2). The floor of the circular arena was virtually divided into two zones, namely the center $(70 \mathrm{~cm})$ and the periphery. The time spent in these two defined zones was recorded during 10 min with the same computerized system cited above. Results are expressed as the fraction of total exploratory time spent in the central zone, as well as other parameters like the number of entries in center, the latency of the first entrance to the center, central vs. total walking ratio, locomotion and mean speed of animals. 


\subsection{Resident intruder test (RIT)}

Mice were tested for offensive aggressive behavior using the resident-intruder paradigm either one (W1) or 21 days (W21) post-treatment, as described (Koolhaas et al., 2013). Briefly, each mouse (resident) was housed with a female for at least one week before the test day. This fact facilitated the development of territoriality and prevented social isolation. The females were previously sterilized by ligation of the oviducts, so they were regularly receptive without becoming pregnant and developing maternal aggression. On the experiment day, the female was removed from the residential cage one hour before the test and an unfamiliar male (intruder) was introduced into the home cage. The resident-intruder interactions were video-recorded for $10 \mathrm{~min}$ and the resident was scored for two general measures of offensive aggression: latency to the first attack and number of attacks. If any signs of suffering or wounds were observed, the animals were immediately separated, and the experiment was terminated. However, no early ending was required in any case.

\subsection{Tissue sample preparations}

Mice were killed by cervical dislocation $2 \mathrm{~h}$ (Day 7) or $24 \mathrm{~h}$ after the treatment (Day 8, W1), as well as 21 days after treatment (Day 28, W21), for the analysis of several factors including Arc, GluA2, CDK5, p35/p25, phospho-Tau (Thr205)/Tau, NFkB, G9a, TH, DAT, D1R, D2R, $\triangle$ FosB, 4-HNE and glial fibrillary acidic protein (GFAP). Orbitofrontal cortex (OFC) and VS (including NAcc) or DS, when appropriate, were quickly dissected out and stored at $-80^{\circ} \mathrm{C}$ until use. Particularly, for the dissection of the OFC, brains were rapidly removed and placed in a mouse brain acrylic matrix (Alto, Agnthos, Sweden) placed on ice. Two double edge blades were used to obtain a $1 \mathrm{~mm}$ thick slice (from 2 to $3 \mathrm{~mm}$ anterior to bregma), that contains the region of interest. The anatomical boundaries for each brain subregion are depicted in Fig. 1B

In order to reduce the number of animals, the VS was used to study the signaling pathways related with neuroplasticity and those considered involved in the rewarding and sensitizing effects, while the DS was reserved to assess the neuroadaptations that take place in the dopaminergic transmission and the possible neurotoxic effects of a repeated exposure to MDPV.

Tissue samples for Western blot analysis were processed as described (Pubill et al., 2013) with minor modifications. Briefly, tissue samples were homogenized at $4{ }^{\circ} \mathrm{C}$ in 20 volumes of lysis buffer (20 mM Tris-HCl, pH=8, 1\% NP40, $137 \mathrm{mM} \mathrm{NaCl,} \mathrm{10 \%} \mathrm{glycerol,} \mathrm{2mM} \mathrm{EDTA)} \mathrm{with} \mathrm{the}$ protease inhibitor cocktail. The homogenates were shaken and rolled for $2 \mathrm{~h}$ at $4{ }^{\circ} \mathrm{C}$ and centrifuged at $15,000 \mathrm{x} \mathrm{g}$ for $30 \mathrm{~min}$ at $4{ }^{\circ} \mathrm{C}$. Aliquots of resulting supernatants (total lysate) were collected and stored at $-80^{\circ} \mathrm{C}$ until use. Protein content was determined using the Bio-Rad Protein Reagent (Bio Rad, Inc., Spain).

\subsection{Dopamine transporter density}

The density of the DA transporter in striatal membranes was measured using [ $\left.{ }^{3} \mathrm{H}\right]$ WIN 35428 binding assays as described previously (López-Arnau et al., 2015). The crude membrane preparation used in the experiments collects both the synaptosomal membrane and the endosomal fraction.

\subsection{Total RNA extraction and Gene Expression determination}


Total RNA isolation from VS was carried out by means of a TRI reagent-Chloroform based extraction protocol. RNA content in the samples was measured at $260 \mathrm{~nm}$, and sample purity was determined by the A260/280 ratio in a NanoDrop ${ }^{\mathrm{TM}}$ ND-1000 spectrophotometer (ThermoFisher Scientific). The isolated mRNA was reverse-transcribed by a Reverse Transcription Polymerase Chain Reaction (RT-PCR) using the High Capacity cDNA Reverse Transcription Kit (Applied Biosystems) and the Veriti ${ }^{\circledR}$ thermal cycler (Applied Biosystems, Foster, CA, USA). Briefly, complementary DNA (cDNA) was synthesized in a total volume of $20 \mu \mathrm{L}$ by mixing $1 \mu \mathrm{g}$ of total RNA and the appropriate volumes of each reagent. The cDNA product was used for subsequent real-time PCR amplification using the Step One Plus ${ }^{\mathrm{TM}}$ Real-Time PCR System (Aplied Biosystems, USA) with 25 ng of the cDNA mixture and the assays-on-demand from Applied Biosystems Mm00479619_g1for Arc, Mm0113261_m1 for G9a and Mm00607939_s1 for Actb as an endogenous control. Fold-changes in gene expression were calculated using the standard comparative Cycle threshold $(\mathrm{Ct})$ method $(\Delta \Delta \mathrm{Ct})$ (Livak and Schmittgen, 2001).

\subsection{Surface receptor cross-linking with $B S^{3}$}

21 days after the last injection of MDPV or saline, mice were killed by cervical dislocation. Accumbal tissue from each mouse was processed for cross-linking assays as described (Boudreau et al., 2007).

\subsection{Western blotting and immunodetection}

A general Western Blotting and immunodetection protocol was used. Briefly, for each sample, $10-25 \mu \mathrm{g}$ of protein was mixed with sample buffer $(0.5 \mathrm{M}$ Tris- $\mathrm{HCl}, \mathrm{pH}=6.8,10 \%$ glycerol, $2 \%$ $(\mathrm{w} / \mathrm{v})$ SDS, $5 \%(\mathrm{v} / \mathrm{v}) 2-\beta$-mercaptoethanol, $0.05 \%$ bromophenol blue), boiled for $5 \mathrm{~min}$ and loaded onto a $10 \%$ acrylamide gel or on a $4-15 \%$ gradient Tris-HCl gel (Bio-Rad, Hercules, $\mathrm{CA}$ ) in the case of the surface receptor cross-linking with $\mathrm{BS}^{3}$. Proteins were electrophoresed and subsequently transferred to polyvinilidene fluoride sheets (PVDF) (Immobilon-P; Millipore, USA). PVDF membranes were blocked for $1 \mathrm{~h}$ at room temperature with $5 \%$ defatted milk in Tris-buffer plus $0.05 \%$ Tween-20 and incubated overnight at $4{ }^{\circ} \mathrm{C}$ with the corresponding primary antibodies (Table 2). After washing, membranes were incubated for $1 \mathrm{~h}$ at room temperature with the corresponding peroxidase-conjugated anti-IgG antibody. Immunoreactive protein was visualized using a chemoluminiscence-based detection kit following the manufacturer's protocol (Immobilion Western, Millipore) and a BioRad ChemiDoc XRS gel documentation system (BioRad, Inc., Madrid, Spain). Scanned blots were analyzed using a BioRad Image Software and dot densities were expressed as a percentage of those taken from the control. As a protein load control, immunodetection of $\beta$-tubulin (1:2500, Sigma Aldrich) or GAPDH (1:5000, Merck Millipore) was used. The whole list of antibodies used in these experiments is contained in supplementary material/table1.

\subsection{Data analysis}

Data from biochemical analyses were normalized with $100 \%$ defined as the mean of the technical replicates in the control group, and the SEM was normalized appropriately. Animals were randomly assigned to an experimental group. During the behavioral manipulations, researchers were not aware of the pretreatment that each animal previously received.

Data were expressed as mean \pm standard error of the mean (SEM). Differences between groups were compared using one or two-way analysis of variance (ANOVA) or Student's test for independent samples where appropriate. Significant differences $(p<0.05)$ were analyzed using 
the Bonferroni post hoc test for multiple comparison measures only when $\mathrm{F}$ achieved the necessary level of statistical significance $(p<0.05)$ and there was no significant variance in homogeneity. The exact group size for the individual experiments is shown in the corresponding figure legends. Statistic calculations were performed using GraphPAD Prism 6.0 software.

\section{RESULTS}

\subsection{Effects of MDPV treatment on anxiety, impulsivity and aggression}

The EPM test was performed in order to assess anxiogenic or anxiolytic effects induced by drug withdrawal. The cathinone derivative did not increase anxiety $48 \mathrm{~h}$ after treatment, since both the control and the MDPV groups displayed a similar anxious-behavior after a continued treatment (saline: open arms $53.90 \pm 8.28 \mathrm{~s}$; closed arms: $126.91 \pm 10.58 \mathrm{~s}, \mathrm{t}_{10}=3.879 P<0.01$; MDPV: open arms $41.33 \pm 8.62 \mathrm{~s}$; closed arms $121.59 \pm 18.30 \mathrm{~s}, \mathrm{t}_{8}=3.023, \mathrm{P}<0.05$ ). Nevertheless, after 21 days of withdrawal (W21), when EPM was carried out in a different batch of animals, the saline group did not show differences between open and closed arms (open arms $81.78 \pm 13.27 \mathrm{~s}$, closed arms $\left.111.62 \pm 8.04 \mathrm{~s}, \mathrm{t}_{6}=1.915, \mathrm{n} . \mathrm{s}\right)$, while MDPV-treated mice still presented an anxious-behavior, that is, the animals spent significantly more time in the closed arms than in the open (open arms $57.16 \pm 11.45 \mathrm{~s}$, closed arms $118.38 \pm 16.85 \mathrm{~s}, \mathrm{t}_{7}=$ 2.315, $P=0.05)$ ) (Fig. 2B). Two-way ANOVA analysis of the time spent in the open arms, which is the main parameter measuring anxiety-like behavior, revealed a significant effect of treatment $\left(\mathrm{F}_{1,33}=4.280, P=0.0465\right)$, with lower values in the MDPV group, and also of time $\left(\mathrm{F}_{1,33}=5.429, P=0.0261\right)(\mathrm{W} 2$ : saline $\mathrm{n}=11$ and MDPV $\mathrm{n}=9$; W21: saline $\mathrm{n}=7$ and MDPV $\mathrm{n}=8)($ Fig. $2 \mathrm{~A})$.

In the $\mathrm{OF}$, the behavior of both groups started to diverge until reaching statistical significance on day W21 (Fig. 2B; two-way ANOVA: variable treatment $\mathrm{F}_{1,13}=5.687, P=0.0330$, variable time $\mathrm{F}_{1,13}=34.560 P=0001$; interaction $\mathrm{F}_{1,13}=5.974, P=0.0295$; saline $\mathrm{n}=7$ and MDPV $\mathrm{n}=8$ ). Specifically, MDPV-treated mice spent more time in the central area of the arena, considered aversive, compared with the control group, aside from exhibiting a more central vs. total walking ratio, a shorter latency in the first entrance to the center, and a higher but not significant number of entries in the center (Fig. 2B, Table 1). Overall, there were no significant differences between MDPV and saline-treated mice regarding to the speed and total distance travelled in every trial (Table 1).

Increased aggressiveness was demonstrated in the RIT. Two-way ANOVA analysis of the latency to the first attack showed a significant effect of variable treatment ( $F 1,17=4.456$, $P=0.0499)$ and withdrawal time $(\mathrm{F} 1,17=7.303, P=0.0151)$. The same statistical analysis applied to the number of attacks exhibited a significant dependence of the variable withdrawal time $(\mathrm{F} 1,17=8.215, P=0.0107)$ and the interaction treatment $\mathrm{x}$ time $(\mathrm{F} 1,17=10.730, P=0.0045)$ (saline $\mathrm{n}=9$ and MDPV $\mathrm{n}=10$ ). Post-hoc analysis indicated that adolescent mice of MDPV group, at W1, showed a shorter latency time to first attack than saline group. Aggressive behavior was also supported by the fact that the attacks by MDPV-treated mice were much more frequent (Fig. 2C, 2D). When this behavior was re-evaluated 21 days after, when the animals had already reached adulthood, the saline group showed a shorter latency to first attack than the adolescent, probably due to the fact that adults show a greater territorial behavior. However, the number of attacks of the MDPV group at W21 did not differ from that of saline. 
Therefore, MDPV only increased aggressive behavior when tested shortly after exposure, an effect that disappeared after the long withdrawal.

\subsection{Transcriptional mechanisms activated after a chronic exposure to MDPV}

Once the treatment with MDPV was finished, the expression of several factors in the striatum was determined by Western blot, qPCR and radioligand binding assays.

\subsection{Expression of factors related to neuroplasticity, sensitizing and reinforcing effects in the ventral striatum (including NAcc)}

Arc levels were determined in the striatum $2 \mathrm{~h}$ after the treatment with MDPV, showing a significant increase compared with the saline group $\left(\mathrm{t}_{10}=2,567, P=0.0280, \mathrm{n}=6\right.$ per group) (Fig. $3 A)$. Interestingly, the Arc expression decreased after MDPV withdrawal $\left(\mathrm{t}_{8}=2.71, P=0.0254\right.$, $\mathrm{n}=5$ per group) (Fig. 3B). Due to this unexpected result, the mRNA levels encoding $\operatorname{Arc}$ were quantified by qPCR in the VS of saline and MDPV-treated mice, on W21. MDPV-mice presented significantly higher levels (37\%) of $\operatorname{Arc}$ mRNA (Fig. 3B, inset) $\left(\mathrm{t}_{12}=2.281, P=0.0416\right.$, saline $n=8$ and MDPV $n=6$ ).

On the other hand, some of the validated target genes for $\triangle \mathrm{FosB}$ in nucleus accumbens, such as CDK5, GluA2, and NFkB, were assayed. Additionally to the higher levels of $\triangle \mathrm{FosB}, \mathrm{W} 1$ MDPV-treated mice showed a significant increase of $29 \%$ in CDK5 expression $\left(\mathrm{t}_{10}=4.783\right.$, $P=0.0007, \mathrm{n}=6$ per group) (Fig.3C). However, this increase was not accompanied by a pathological activation of the protein as the ratio p35/p25 did not show significant differences between the groups of treatment ( $\mathrm{t}_{10}=0,276$, n.s.; $\mathrm{n}=6$ per group). Accordingly, the levels of phospho-Tau (Thr205)/Tau were not altered by MDPV exposure $\left(\mathrm{t}_{10}=1,192\right.$, n.s., $\mathrm{n}=6$ per group) (Fig. 3E and 3F). Moreover, a 29\% increase in CDK5 levels was also found after the MDPV withdrawal (W21) ( $\mathrm{t}_{8}=1.871, P=0.0492, \mathrm{n}=5$ per group) (Fig. 3D). This increase was the same as that seen $24 \mathrm{~h}$ post-treatment, suggesting a stable overexpression of this factor during the withdrawal.

Another $\triangle \mathrm{FosB}$ target assayed was NFкB. In VS this factor remained unaffected just after treatment with MDPV (saline: $100 \pm 4.78 \%$; MDPV: $101.51 \pm 5.29 \%, \mathrm{t}_{10}=0.212$, n.s., $\mathrm{n}=6$ per group).

No change in GluA2 expression was detected in VS at W1 (saline: $100 \pm 8.74 \%$; MDPV: $106.70 \pm 14.16 \%, \mathrm{t}_{10}=0.402$, n.s., $\mathrm{n}=6$ per group). However, on $\mathrm{W} 21$, the levels were halved $\left(\mathrm{t}_{8}\right.$ $=3.090, P=0.0149$, saline $\mathrm{n}=5$ and MDPV $\mathrm{n}=4$ ). At this time, an apparent internalization of this subunit was obtained, although it did not reach statistical significance $\left(\mathrm{t}_{10}=1.817\right.$, n.s., $\mathrm{n}=6$ per group) (Fig. 3G and 3H).

We also determined G9a expression through quantification of mRNA encoding $G 9 a$ gene in VS, $24 \mathrm{~h}$ after repeated MDPV exposure. Surprisingly, the results showed a significant increase in G9a transcription in the MDPV group ( $\mathrm{t}_{8}=4.229, P=0.0029, \mathrm{n}=5$ per group) (Fig. 4).

\subsubsection{Expression of factors related with dopaminergic transmission in the dorsal striatum}

The levels of D1R were significantly increased in MDPV-treated mice 24h after the treatment $\left(\mathrm{t}_{10}=3.289, P=0.0082, \mathrm{n}=6\right.$ per group) (Fig. $5 \mathrm{~A}$ ). Also, as reported previously, D2R levels were significantly lower in MDPV mice (saline: $100 \pm 7.68 \%$, MDPV: $73.70 \pm 6.59 \%$ ), therefore, the 
ratio D2R:D1R points to a preponderance of D1R. After the withdrawal (W21) the MDPV group showed a significant decrease of around $25 \%$ in the population of $\mathrm{D} 1 \mathrm{R},\left(\mathrm{t}_{8}=2.931\right.$, $P=0.0190, \mathrm{n}=5$ per group) (Fig. 5B), while D2R levels remained stable (data not shown). Therefore, the D2R:D1R ratio changed again.

$\mathrm{TH}$, the key enzyme for the biosynthesis of DA, was up-regulated $24 \mathrm{~h}$ after dosing $\left(\mathrm{t}_{10}=2,573\right.$, $P=0.0277, \mathrm{n}=6$ per group) and its overexpression persisted during withdrawal $\left(\mathrm{t}_{8}=2.316\right.$, $P=0.0492$, saline $\mathrm{n}=5$ and MDPV $\mathrm{n}=5$ ) (Fig. 5C and 5D).

Finally, we measured the levels of $\left[{ }^{3} \mathrm{H}\right]$ WIN 35428 bound to a crude membrane preparation of the striatum, as a marker of DAT in dopaminergic terminals. No changes were observed in DAT shortly after MDPV exposure (W1) ( $t_{9}=0.355$, n.s., saline $n=5$ and MDPV $\left.n=6\right)$. However, when binding was assessed after withdrawal (W21) DAT levels were significantly decreased $\left(\mathrm{t}_{14}=2.484, P=0.0264, \mathrm{n}=8\right.$ per group) (Fig. $5 \mathrm{E}$ and $\left.5 \mathrm{~F}\right)$.

\subsection{Neurotoxic effects of MDPV in dorsal striatum}

In order to assess any possible neurotoxic effect of the repeated exposure to the drug, 4-HNE, a marker of lipid peroxidation, and GFAP were measured. 24h after treatment, 4-HNE increased by almost 200\% (Saline: $100 \pm 19 \%$; MDPV: $296.51 \pm 35.16 \%, \mathrm{t}_{10}=4.889, P=0.0006, \mathrm{n}=6$ per group) possibly due to the synaptic oxidation of DA and quinones formation, while no changes were observed in GFAP expression (Saline: $100 \pm 14 \%$; MDPV: $100.89 \pm 13.13 \%, \mathrm{t}_{10}=0,046$, n.s., $\mathrm{n}=6$ per group). Considering these results, we also assessed the levels of the same markers at W21, since the GFAP response could be delayed in time. The expression of this glial protein, however, remained unaltered (saline: $100 \pm 27.78 \%$; MDPV: $92.42 \pm 16.84 \%, \mathrm{t}_{8}=0.233$, n.s., $\mathrm{n}=5$ per group). On the other hand, 4-HNE levels decreased to be non-significantly different from saline group (saline: $100 \pm 9.06 \%$; MDPV: $84.77 \pm 5.62 \%, \mathrm{t}_{10}=1.429$, n.s., $\mathrm{n}=6$ per group), suggesting a transient pro-oxidative effect of MDPV.

\subsection{Effects of MDPV treatment on $\triangle F o s B$ expression in the orbitofrontal cortex after withdrawal}

Some data indicate that the induction of $\triangle \mathrm{FosB}$ within the OFC plays a key role in the deficit in impulse control mediated by cocaine (Winstanley et al., 2009). In light of our results in the OF paradigm, we determined how the MDPV treatment might have altered the expression of this transcription factor in the OFC at the same time point we had evidenced significant differences in the OF paradigm, (W21). In this area, MDPV induced a significant increase of $\triangle \mathrm{FosB}$ expression (saline: $100 \pm 19.65 \%$; MDPV: $175.76 \pm 15.84 \%, \mathrm{t}_{9==3} 3.04, P=0.0140$; saline $\mathrm{n}=5$ per group and MDPV $n=6$ per group).

\section{DISCUSSION}

In the present work, we studied the behavioral and neuroadaptive changes induced by a sensitizing MDPV exposure. The most important results from the behavioral experiments are the long-lasting anxiogenic effect, the increase in high risk-taking behavior and the aggressiveness evidenced shortly after the MDPV treatment. At the same time, MDPV triggers a transcriptional machinery similar to that of cocaine, although some differences must be highlighted. 
Initially, the animals were evaluated for anxiety, habituation and aggressiveness using the EPM, OF and RIT paradigms, respectively. Regarding to the EPM, the repeated exposure to MDPV caused an anxiogenic effect (more time in the closed arms) that is apparent mainly long after treatment, when animals have become adults.

The anxiogenesis displayed by the animals treated with the cathinone derivative suggests changes in other behavioral issues. A simple way to observe these changes is in the $\mathrm{OF}$, so we proceeded to assess various parameters of mice activity in this paradigm, which provides an initial screen for emotional-related behavior (Bailey and Crawley, 2009). After habituation (W3, W21), MDPV-treated mice ventured more frequently into the central area, so permanence in the center increased without changing the pattern of locomotor activity or the mean speed. The time spent in the center area in the OF involves leaving a defensive zone to enter in a more exposed zone, so it can be interpreted as a faster habituation to the new environment favoring this risky behavior (Clément et al., 1995). It cannot be attributed to an anxiolytic effect, because actually, in the EPM paradigm, MDPV has rather the opposite effect. This particular pattern of behavior in the OF is also observed some days after ending a long-term treatment with MDMA (Abad et al., 2013; Mechan et al., 2002), although, as it occurs with MDPV, exposure to MDMA induced a lasting anxiogenic response in the EPM (Rodríguez-Arias et al., 2011). Repeated exposure to the OF test, as in our experiments, provides a method for assessing habituation to the increasingly familiar chamber environment. After repeated exposure to MDMA or MDPV, animals adapt faster to the repeated social isolation resulting from the physical separation from cage mates when performing the OF test, and the stress created by the brightly lit, unprotected novel test environment.

In addition to the effect of MDPV on anxiety and habituation, we assessed aggressiveness. Based on case studies, MDPV, as other cathinone derivatives, tends to produce increased aggressive behavior (James et al., 2011; Murray et al., 2012; Penders et al., 2012). In our study we evidenced that territorial aggression was increased in the MDPV group when it was tested shortly after the treatment. This is the first time in the literature reporting that MDPV exposure can increase the aggressive behavior in mice. In humans, it is suggested a role of the D2 receptors in pathological aggressive behavior. Chen et al. (2005) observed a correlation between the dopamine D2 receptor gene and DAT gene polymorphisms with pathological violence in adolescents, in a blinded clinical trial, linking hypo-activation of striatal and prefrontal areas to disease severity. Therefore, we cannot rule out the possibility that the changes in dopaminergic neurotransmission evidenced early after MDPV exposure could contribute to the aggressiveness induced by MDPV. This behavioral effect declined upon withdrawal, when the D2/D1 ratio recovered and synaptic DA clearance by DAT was reduced.

Another purpose of the present study was to investigate changes in specific neuronal biomarkers after a sensitization regime of MDPV, which could explain the increased sensibility to cocaine effects long after MDPV exposure. In this sense, the activation of immediate early genes, such as Arc, by psychomotor stimulants has been interpreted primarily as a key step influencing longterm plasticity in neurons (Nestler, 2001). In our study, MDPV-treated mice showed an early increase of Arc protein levels, which significantly reversed after withdrawal. After this result we wanted to find an explanation for this decline, measuring the expression of the gene encoding Arc. The observed discrepancy between Arc mRNA and protein levels under these circumstances was also described for cocaine (Fumagalli et al., 2006), and it was attributed to a reduced Arc mRNA turnover or to an inhibition of protein synthesis. However, we cannot rule out that the accompanying increase in protein could not be detected because the protein had 
been specifically targeted to dendrites/synapses after long stimulation periods. Our results regarding Arc are relevant, as this protein is considered a reliable index of activity-dependent synaptic modifications (Larsen et al., 2005), and its overexpression was also reported after chronic cocaine treatment (Fumagalli et al., 2006). In this sense, Arc has also been associated to altered morphology of dendrites and spines observed after this drug exposure. In this sense, our results suggest that there is a high probability that the repeated treatment with MDPV also causes a structural modification of these neuronal elements.

As previously reported (López-Arnau et al., 2017), repeated exposure of adolescent mice to MDPV increases $\triangle$ FosB expression in the VS $24 \mathrm{~h}$ after ending the treatment $(\approx 290 \%)$ and, although it declined during the 21 days of withdrawal, this factor remained increased $(\approx 135 \%)$. Additionally, we measured $\triangle \mathrm{FosB}$ in OFC, because a relationship between its overexpression in this brain area and an increase in risk-taking behavior and locomotor sensitization to cocaine has been demonstrated (Winstanley et al., 2009). In our study, the animals that received MDPV showed an increase of $\triangle F$ FosB in the OFC of about $75 \%$ after withdrawal which is, in fact, more than double of that registered in the VS. Therefore, the sensitization of MDPV-treated animals to the locomotor-psychostimulant properties of cocaine is associated to increased levels of $\triangle \mathrm{FosB}$ in the VS and the $\mathrm{OFC}$, with this latter area showing a much higher increase. Accordingly, we cannot rule out that the changes in $\Delta \mathrm{FosB}$ in both areas contribute to the increased sensitivity to this psychostimulant.

It is known that $\Delta \mathrm{FosB}$ is involved in close to one quarter of all the genes influenced by chronic cocaine exposure in the NAcc and it functions primarily as a transcriptional activator or as a repressor, depending on the duration and the degree of its expression (Nestler, 2008). CDK5 is also an example of a gene that is induced by chronic, but not acute, cocaine administration (Bibb et al., 2001) and the activation of CDK5 is not only under positive control of $\triangle$ FosB but is also regulated by extracellular signal-regulated kinase (ERK) whose phosphorylation is increased in the NAcc by drugs of abuse through a dopamine D1 receptor-dependent mechanism (Valjent et al., 2004). In our experiments, MDPV-treated mice showed a significant increase in CDK5 levels, and this overexpression was still apparent after 3 weeks of withdrawal, even in the same percentage. Thus, unlike $\Delta \mathrm{FosB}$, which declined over time, the expression of CDK5 remained stable during the whole experiment. Therefore, we cannot rule out that the hyperdopaminergic state observed in mice after repeated doses of MDPV activates the MAPK/ERK pathway that contributes to the stable effect of the CDK5.

On the other hand, it is known that CDK5 controls dopamine neurotransmission through the regulation of DARPP-32, a protein phosphatase-1 inhibitor. In this way, CDK5 mediates cellular responses to cocaine-induced changes in dopamine signal transduction and cytoskeletal reorganization (Bibb et al., 2001). Therefore, this kinase is also a key element for the plasticity observed after the chronic administration of cocaine. Benavides and Bibb (2004) suggested a model of cellular signalling pathways under control of CDK5, whose activation takes place downstream of the overactivation of D1 receptors after cocaine administration. Given that MDPV has the same pharmacological mechanism of action, we might expect a similar chain of events to those suggested for cocaine under control of CDK5. Moreover, we also wanted to investigate if CDK5 activation could also lead to an abnormal phosphorylation of the TAU protein, whose consequences are well known. Although MDPV-treated mice showed increased levels of CDK5, when the p35/p25 and phosphor-Tau (Thr205)/Tau ratios were measured no differences between groups were found. Moreover, the levels of p35 were much higher than p25, suggesting an activation of CDK5. 
$\triangle$ FosB also regulates the AMPA receptor GluA2 subunit (Kelz et al., 1999; McClung and Nestler, 2003). GluA2-containing AMPARs are downregulated after prolonged withdrawal (3549 days) from cocaine self-administration leading to an internalization of this subunit (Boudreau et al., 2007), but not after prolonged withdrawal from no contingent cocaine injections. In the present study, repeated non-contingent administration of MDPV did not produce any acute effect on AMPA receptors but, during withdrawal, the adaptive changes produced a very significant decrease of the GluA2 subunit. We may speculate that this adaptation of the AMPA receptor is the result of an increased glutamatergic neurotransmission, as described for cocaine (for review see Vandershuren and Kalivas 2000). Likewise, the glutamate system has been associated with the reinforcing and psychostimulant properties of MDPV (Gregg et al, 2016).

In this study we also investigated the influence of epigenetic changes induced by MDPV, as these effects have already been described for cocaine. Epigenetic changes have been revealed as critical mechanisms contributing to drug-induced plasticity by regulating gene expression. G9a specifically catalyzes the demethylation of lysine 9 of histone 3(H3K9me2). Maze et al (2010) showed that acute cocaine increases G9a levels in the NAcc. In contrast, they found a downregulation of G9a $24 \mathrm{~h}$ after repeated cocaine administration consistent with an overexpression of some target genes such as $\operatorname{Arc}$ (Oey et al., 2015) and $\Delta$ FosB (Maze et al., 2010). As $\Delta$ FosB accumulates, it represses G9a and thereby potentiates its own further induction. In our work, an overexpression of this transferase has been observed in the VS 24h after the treatment. Possibly, if this repressor transferase was not increased, the overexpression of $\Delta \mathrm{FosB}$ and Arc would be much higher and last longer (as with cocaine). Also, this suggests that another additional factor to $\Delta$ FosB could modulate the expression of G9a.

Due to MDPV has the same mechanism of action as cocaine, we also studied the evolution of parameters related to dopaminergic neurotransmission in the DS. Repeated cocaine exposure led to expected short-term changes such as increase of TH expression in NAcc (Rodriguez-Espinosa and Fernandez-Espejo, 2015). In parallel, MDPV exposure also increased the expression of TH in DS shortly after treatment and 21 days later, suggesting a long-lasting adaptive change in this gene expression, probably regulated by several mechanisms (Kumer and Vrana, 1996) as CDK5. It is known that increased dopamine uptake through its specific transporter results in oxidative damage via the cytosolic oxidation of this neurotransmitter (Masoud et al., 2015). Therefore, in the animals that developed a hyperdopaminergic status, the reduction of DAT found after MDPV guarantees a resilience response to avoid terminal injury by oxygen radicals derived from high DA intracellular levels

In vivo, chronic cocaine use is accompanied by an immediate change in the D2R:D1R ratio signaling towards the D1R (Thompson et al., 2010). In the present study, D1R population increased while D2R was reduced in MDPV treated mice. Hence, the D2R:D1R ratio decreased approximately by half. However, three weeks post-treatment, the ratio D2R:D1R increased. These changes ran in parallel with the increased TH levels and the lower removal of DA from synapses via DAT, pointing to an hyperdopaminergic status. All these effects are probably due to adaptive neuroplastic changes associated to MDPV abuse and withdrawal.

Considering that MDPV generates a hyperdopaminergic status, and that high levels of DA can cause oxidative reactions, 4-HNE, a robust marker of oxidative stress (Perluigi et al., 2012) and GFAP, which indicates glial activation, were assessed to investigate a putative neurotoxic effect of the cathinone. Shortly after drug exposure we found that 4-HNE levels had tripled, pointing 
to an important oxidative effect generated by DA or by the MDPV metabolism to reactive quinones (Baumann et al., 2017). However, after withdrawal, this pathophysiological sign had been overcome. On the other hand, GFAP levels remained unaltered the whole time--suggesting that this oxidative stress is not severe enough to trigger an astroglial response. These results suggest that, although there is significant oxidative effect, it is transient and without relevant consequences.

In conclusion, repeated MDPV exposure in mice induces anxiogenic effects and increases aggressiveness. We speculate that increased levels of $\triangle \mathrm{FosB}$ in VS but also in the OFC can contribute to locomotor sensitization. Other signals that persist long after withdrawal probably also contribute to the sensitization to MDPV as Arc and CDK5 overexpression, changes in D2R/D1R ratio, high levels of TH and a low DA clearance by DAT, pointing to a disorder of DA imbalance promoted by MDPV (i.e., long-lasting hyperdopaminergic status). Given that MDPV has the same mechanism of action as cocaine, a similar chain of events modulated mainly by CDK5 can be hypothesized. Although repeated exposure to MDPV resulted in an increase in $\triangle \mathrm{FosB}$, as it occurs after cocaine exposure, we did not observe an increase in NFKB or GluA2. This may be due to the fact that, in addition to the regulatory autoloop described for cocaine between $\mathrm{G} 9 \mathrm{a}$ and $\triangle \mathrm{FosB}$, there might be other independent regulatory signals modulating $\triangle \mathrm{FosB}$ and its target genes.

\section{REFERENCES}

Aarde, S.M., Huang, P.K., Creehan, K.M., Dickerson, T.J., Taffe, M.A., 2013. The novel recreational drug 3,4-methylenedioxypyrovalerone (MDPV) is a potent psychomotor stimulant: self-administration and locomotor activity in rats. Neuropharmacology 71 , 130-140. https://doi.org/10.1016/j.neuropharm.2013.04.003

Abad, S., Fole, A., Del Olmo, N., Pubill, D., Pallàs, M., Junyent, F., Camarasa, J., Camins, A., Escubedo, E., 2013. MDMA enhances hippocampal-dependent learning and memory under restrictive conditions, and modifies hippocampal spine density. Psychopharmacology (Berl.). https://doi.org/10.1007/s00213-013-3304-5

Bailey, K.R., Crawley, J.N., 2009. Anxiety-Related Behaviors in Mice, in: Buccafusco, J.J. (Ed.), Methods of Behavior Analysis in Neuroscience, Frontiers in Neuroscience. CRC Press/Taylor \& Francis, Boca Raton (FL).

Baumann, M.H., Bukhari, M.O., Lehner, K.R., Anizan, S., Rice, K.C., Concheiro, M., Huestis, M.A., 2017. Neuropharmacology of 3,4-Methylenedioxypyrovalerone (MDPV), Its Metabolites, and Related Analogs. Curr. Top. Behav. Neurosci. 32, 93-117. https://doi.org/10.1007/7854_2016_53

Baumann, M.H., Partilla, J.S., Lehner, K.R., Thorndike, E.B., Hoffman, A.F., Holy, M., Rothman, R.B., Goldberg, S.R., Lupica, C.R., Sitte, H.H., Brandt, S.D., Tella, S.R., Cozzi, N.V., Schindler, C.W., 2013. Powerful cocaine-like actions of 3,4methylenedioxypyrovalerone (MDPV), a principal constituent of psychoactive "bath salts" products. Neuropsychopharmacol. Off. Publ. Am. Coll. Neuropsychopharmacol. 38, 552-562. https://doi.org/10.1038/npp.2012.204

Bibb, J.A., Chen, J., Taylor, J.R., Svenningsson, P., Nishi, A., Snyder, G.L., Yan, Z., Sagawa, Z.K., Ouimet, C.C., Nairn, A.C., Nestler, E.J., Greengard, P., 2001. Effects of chronic exposure to cocaine are regulated by the neuronal protein Cdk5. Nature 410, 376-380. https://doi.org/10.1038/35066591

Boudreau, A.C., Reimers, J.M., Milovanovic, M., Wolf, M.E., 2007. Cell surface AMPA receptors in the rat nucleus accumbens increase during cocaine withdrawal but internalize after cocaine challenge in association with altered activation of mitogen-activated protein 
kinases. J. Neurosci. Off. J. Soc. Neurosci. 27, 10621-10635.

https://doi.org/10.1523/JNEUROSCI.2163-07.2007

Clément, Y., Martin, B., Venault, P., Chapouthier, G., 1995. Involvement of regions of the 4th and 7th chromosomes in the open-field activity of mice. Behav. Brain Res. 70, 51-57.

Fumagalli, F., Bedogni, F., Frasca, A., Di Pasquale, L., Racagni, G., Riva, M.A., 2006.

Corticostriatal up-regulation of activity-regulated cytoskeletal-associated protein expression after repeated exposure to cocaine. Mol. Pharmacol. 70, 1726-1734. https://doi.org/10.1124/mol.106.026302

James, D., Adams, R.D., Spears, R., Cooper, G., Lupton, D.J., Thompson, J.P., Thomas, S.H.L., National Poisons Information Service, 2011. Clinical characteristics of mephedrone toxicity reported to the U.K. National Poisons Information Service. Emerg. Med. J. EMJ 28, 686-689. https://doi.org/10.1136/emj.2010.096636

Kalivas, P.W., Stewart, J., 1991. Dopamine transmission in the initiation and expression of drug- and stress-induced sensitization of motor activity. Brain Res. Rev. 16, 223-244. https://doi.org/10.1016/0165-0173(91)90007-U

Kelz, M.B., Chen, J., Carlezon, W.A., Whisler, K., Gilden, L., Beckmann, A.M., Steffen, C., Zhang, Y.J., Marotti, L., Self, D.W., Tkatch, T., Baranauskas, G., Surmeier, D.J., Neve, R.L., Duman, R.S., Picciotto, M.R., Nestler, E.J., 1999. Expression of the transcription factor deltaFosB in the brain controls sensitivity to cocaine. Nature 401, 272-276. https://doi.org/10.1038/45790

Koolhaas, J.M., Coppens, C.M., de Boer, S.F., Buwalda, B., Meerlo, P., Timmermans, P.J.A., 2013. The Resident-intruder Paradigm: A Standardized Test for Aggression, Violence and Social Stress. J. Vis. Exp. https://doi.org/10.3791/4367

Kumer, S.C., Vrana, K.E., 1996. Intricate regulation of tyrosine hydroxylase activity and gene expression. J. Neurochem. 67, 443-462.

Larsen, M.H., Olesen, M., Woldbye, D.P.D., Hay-Schmidt, A., Hansen, H.H., Rønn, L.C.B., Mikkelsen, J.D., 2005. Regulation of activity-regulated cytoskeleton protein (Arc) mRNA after acute and chronic electroconvulsive stimulation in the rat. Brain Res. 1064, 161-165. https://doi.org/10.1016/j.brainres.2005.09.039

Livak, K.J., Schmittgen, T.D., 2001. Analysis of relative gene expression data using real-time quantitative PCR and the 2(-Delta Delta C(T)) Method. Methods San Diego Calif 25, 402-408. https://doi.org/10.1006/meth.2001.1262

López-Arnau, R., Luján, M.A., Duart-Castells, L., Pubill, D., Camarasa, J., Valverde, O., Escubedo, E., 2017. Exposure of adolescent mice to 3,4-methylenedioxypyrovalerone increases the psychostimulant, rewarding and reinforcing effects of cocaine in adulthood. Br. J. Pharmacol. 174, 1161-1173. https://doi.org/10.1111/bph.13771

López-Arnau, R., Martínez-Clemente, J., Rodrigo, T., Pubill, D., Camarasa, J., Escubedo, E., 2015. Neuronal changes and oxidative stress in adolescent rats after repeated exposure to mephedrone. Toxicol. Appl. Pharmacol. 286, 27-35. https://doi.org/10.1016/j.taap.2015.03.015

Masoud, S.T., Vecchio, L.M., Bergeron, Y., Hossain, M.M., Nguyen, L.T., Bermejo, M.K., Kile, B., Sotnikova, T.D., Siesser, W.B., Gainetdinov, R.R., Wightman, R.M., Caron, M.G., Richardson, J.R., Miller, G.W., Ramsey, A.J., Cyr, M., Salahpour, A., 2015. Increased expression of the dopamine transporter leads to loss of dopamine neurons, oxidative stress and I-DOPA reversible motor deficits. Neurobiol. Dis. 74, 66-75. https://doi.org/10.1016/j.nbd.2014.10.016

Maze, I., Covington, H.E., Dietz, D.M., LaPlant, Q., Renthal, W., Russo, S.J., Mechanic, M., Mouzon, E., Neve, R.L., Haggarty, S.J., Ren, Y., Sampath, S.C., Hurd, Y.L., Greengard, P., Tarakhovsky, A., Schaefer, A., Nestler, E.J., 2010. Essential role of the histone methyltransferase G9a in cocaine-induced plasticity. Science 327, 213-216. https://doi.org/10.1126/science.1179438 
McClung, C.A., Nestler, E.J., 2003. Regulation of gene expression and cocaine reward by CREB and $\Delta$ FosB. Nat. Neurosci. 6, 1208-1215. https://doi.org/10.1038/nn1143

McClung, C.A., Ulery, P.G., Perrotti, L.I., Zachariou, V., Berton, O., Nestler, E.J., 2004. DeltaFosB: a molecular switch for long-term adaptation in the brain. Brain Res. Mol. Brain Res. 132, 146-154. https://doi.org/10.1016/j.molbrainres.2004.05.014

McKerchar, T.L., Zarcone, T.J., Fowler, S.C., 2005. Differential acquisition of lever pressing in inbred and outbred mice: comparison of one-lever and two-lever procedures and correlation with differences in locomotor activity. J. Exp. Anal. Behav. 84, 339-356.

Mechan, A.O., Esteban, B., O'Shea, E., Elliott, J.M., Colado, M.I., Green, A.R., 2002. The pharmacology of the acute hyperthermic response that follows administration of 3,4methylenedioxymethamphetamine (MDMA, 'ecstasy') to rats. Br. J. Pharmacol. 135, 170-180. https://doi.org/10.1038/sj.bjp.0704442

Murray, B.L., Murphy, C.M., Beuhler, M.C., 2012. Death following recreational use of designer drug "bath salts" containing 3,4-Methylenedioxypyrovalerone (MDPV). J. Med. Toxicol. Off. J. Am. Coll. Med. Toxicol. 8, 69-75. https://doi.org/10.1007/s13181-011-0196-9

Nestler, E.J., 2001. Molecular basis of long-term plasticity underlying addiction. Nat. Rev. Neurosci. 2, 119-128. https://doi.org/10.1038/35053570

Nikolic, M., Dudek, H., Kwon, Y.T., Ramos, Y.F., Tsai, L.H., 1996. The cdk5/p35 kinase is essential for neurite outgrowth during neuronal differentiation. Genes Dev. 10, 816825.

Oey, N.E., Leung, H.W., Ezhilarasan, R., Zhou, L., Beuerman, R.W., VanDongen, H.M.A., VanDongen, A.M.J., 2015. A Neuronal Activity-Dependent Dual Function ChromatinModifying Complex Regulates Arc Expression(1,2,3). eNeuro 2. https://doi.org/10.1523/ENEURO.0020-14.2015

Patrick, G.N., Zukerberg, L., Nikolic, M., Monte, S. de la, Dikkes, P., Tsai, L.-H., 1999. Conversion of p35 to p25 deregulates Cdk5 activity and promotes neurodegeneration. Nature 402, 615-622. https://doi.org/10.1038/45159

Paxinos, G., Franklin, K.B.J., 2004. The Mouse Brain in Stereotaxic Coordinates. Gulf Professional Publishing.

Penders, T.M., Gestring, R.E., Vilensky, D.A., 2012. Excited delirium following use of synthetic cathinones (bath salts). Gen. Hosp. Psychiatry 34, 647-650. https://doi.org/10.1016/j.genhosppsych.2012.06.005

Perluigi, M., Coccia, R., Butterfield, D.A., 2012. 4-Hydroxy-2-Nonenal, a Reactive Product of Lipid Peroxidation, and Neurodegenerative Diseases: A Toxic Combination Illuminated by Redox Proteomics Studies. Antioxid. Redox Signal. 17, 1590-1609. https://doi.org/10.1089/ars.2011.4406

Pubill, D., Garcia-Ratés, S., Camarasa, J., Escubedo, E., 2013. 3,4-Methylenedioxymethamphetamine induces in vivo regional up-regulation of central nicotinic receptors in rats and potentiates the regulatory effects of nicotine on these receptors. Neurotoxicology 35, 41-49. https://doi.org/10.1016/j.neuro.2012.11.008

Robinson, T.E., Berridge, K.C., 1993. The neural basis of drug craving: an incentive-sensitization theory of addiction. Brain Res. Brain Res. Rev. 18, 247-291.

Rodríguez-Arias, M., Maldonado, C., Vidal-Infer, A., Guerri, C., Aguilar, M.A., Miñarro, J., 2011. Intermittent ethanol exposure increases long-lasting behavioral and neurochemical effects of MDMA in adolescent mice. Psychopharmacology (Berl.) 218, 429-442. https://doi.org/10.1007/s00213-011-2329-x

Rodriguez-Espinosa, N., Fernandez-Espejo, E., 2015. Effects of acute and repeated cocaine on markers for neural plasticity within the mesolimbic system in rats. Psychopharmacology (Berl.) 232, 57-62. https://doi.org/10.1007/s00213-014-3632-0

Schmidt, H.D., McGinty, J.F., West, A.E., Sadri-Vakili, G., 2013. Epigenetics and psychostimulant addiction. Cold Spring Harb. Perspect. Med. 3, a012047.

https://doi.org/10.1101/cshperspect.a012047 
Simmler, L., Buser, T., Donzelli, M., Schramm, Y., Dieu, L.-H., Huwyler, J., Chaboz, S., Hoener, M., Liechti, M., 2013. Pharmacological characterization of designer cathinones in vitro. Br. J. Pharmacol. 168, 458-470. https://doi.org/10.1111/j.1476-5381.2012.02145.x Thompson, D., Martini, L., Whistler, J.L., 2010. Altered ratio of D1 and D2 dopamine receptors in mouse striatum is associated with behavioral sensitization to cocaine. PloS One 5, e11038. https://doi.org/10.1371/journal.pone.0011038

Watterson, L.R., Hood, L., Sewalia, K., Tomek, S.E., Yahn, S., Johnson, C.T., Wegner, S., Blough, B.E., Marusich, J.A., Olive, M.F., 2012. The Reinforcing and Rewarding Effects of Methylone, a Synthetic Cathinone Commonly Found in "Bath Salts." J. Addict. Res. Ther. Suppl 9. https://doi.org/10.4172/2155-6105.S9-002

Winstanley, C.A., Green, T.A., Theobald, D.E.H., Renthal, W., LaPlant, Q., DiLeone, R.J., Chakravarty, S., Nestler, E.J., 2009. DeltaFosB induction in orbitofrontal cortex potentiates locomotor sensitization despite attenuating the cognitive dysfunction caused by cocaine. Pharmacol. Biochem. Behav. 93, 278-284. https://doi.org/10.1016/j.pbb.2008.12.007

\section{FIGURE LEGENDS}

Fig 1: (A) Drug administration protocol and experimental design. Animals were treated with MDPV or saline two doses in one day (4h apart) during 7 consecutive days. The RIT, EPM and OF paradigms were performed 24h (W1, Day 8), 48h (W2, Day 9) and 72h (W3, Day 10) after treatment, respectively, as well as after 21 days withdrawal (W21, Day 28). Brain samples were collected 2h (Day 7), 24h (W1, Day 8) and 21 days (W21, Day 28) after treatment. (B) Schematic diagram that illustrates the dissection of the orbitofrontal cortex (OFC), dorsal striatum (DS, nucleus caudate/putamen $\mathrm{CPu}$ ) and ventral striatum (VS, including nucleus accumbens shell and core, AcbSh/AcbC) according to the atlas of Paxinos and Franklin (Paxinos and Franklin, 2004).

Fig 2: Behavioral effects of MDPV treatment. (A) EPM results: Bars represent the time spent in the open arms by saline-and MDPV-treated mice in the EPM test $48 \mathrm{~h}$ and 21 days after treatment (W2: saline $n=11$ and MDPV n=9; W21: saline $=7$, MDPV n=8) (B) OF results: Bars represent the time spent by animals in the center of the arena 72h (W3) and 21 days (W21) after treatment with MDPV $(n=8)$ or saline $(n=7)$. (C,D) RIT results: Bars represent both the latency to the first attack as well as the number of attacks in the RIT after $24 \mathrm{~h}$ and 21 days of withdrawal (saline $\mathrm{n}=9$ and MDPV $\mathrm{n}=10$ ). Results are expressed as mean $\pm \mathrm{SEM}$. $\# P<0.05$ vs saline group. ${ }^{\&} P<0.05$ and ${ }^{\& \& \&} P<0.001 \mathrm{~W} 1$ vs treatment-matched W21.

Fig 3: Effect of MDPV treatment on the expression of factors related to neuroplasticity, sensitizing and reinforcing effects in VS: (Aa) Arc protein expression $24 \mathrm{~h}$ ( $\mathrm{n}=6$ per group) and (b) 21 days after treatment ( $n=5$ per group), as well as on mRNA encoding Arc (saline $n=8$ and MDPV n=6) (B, inset). (C) CDK5 expression 24h ( $\mathrm{n}=6$ per group) and (D) 21 days after treatment ( $\mathrm{n}=5$ per group) (E) Ratio $\mathrm{p} 35 / \mathrm{p} 25$ ratio $24 \mathrm{~h}$ after treatment ( $\mathrm{n}=6$ per group) (F) Ratio $\mathrm{p}$-Tau(T205)/total Tau ratio $24 \mathrm{~h}$ after treatment ( $\mathrm{n}=6$ per group). (G) GluA2 expression $24 \mathrm{~h}$ after treatment ( $\mathrm{n}=6$ per group). (H) GluA2 surface/intracellular ratio 21 days post-treatment ( $\mathrm{n}=6$ per group). Results are expressed as mean \pm SEM. $* \mathrm{P}<0.05$ or $* * * \mathrm{P}<0.001$ compared with its corresponding saline group. 
Fig 4: Effect of MDPV treatment on the expression of mRNA encoding G9a methyltransferase in VS $24 \mathrm{~h}$ post-treatment ( $\mathrm{n}=5$ per group). Results are expressed as mean $\pm \mathrm{SEM}$. $* * \mathrm{P}<0.01 \mathrm{vs}$ saline group.

Fig 5: Effect of MDPV treatment on the expression of factors related with dopaminergic transmission in DS: (A) D1R expression $24 \mathrm{~h}$ ( $\mathrm{n}=6$ per group) and (B) 21 days after treatment ( $\mathrm{n}=5$ per group). (C) TH expression $24 \mathrm{~h}$ ( $\mathrm{n}=6$ per group) and (D) 21 days after treatment (saline $\mathrm{n}=5$ and MDPV n=5). (E) DAT density 24h (saline $\mathrm{n}=5$ and MDPV $\mathrm{n}=6$ ) and (F) 21 days after treatment ( $\mathrm{n}=8$ per group). DAT density was measured as $\left[{ }^{3} \mathrm{H}\right]$ WIN 35428 bound. Results are expressed as mean \pm SEM. $* P<0.05$ or $* * P<0.01$ compared with its corresponding saline group.

Table 1: Behavioral parameters registered in the OF test, both 3 and 21 days after treatment (saline $\mathrm{n}=7$ and MDPV $\mathrm{n}=8$ ). The corresponding $\mathrm{F}$ values of the two-way ANOVA analyses are shown below. $* P<0.05$ compared with saline W21 group or ${ }^{\#} P<0.05$ compared with MDPV W3 group using Bonferroni post hoc test.

\section{Supplementary material}

Table S1: Commercial sources and dilution of primary and secondary antibodies used in the Western blot experiments. Brain region and time point of the measure are specified for each target. 
Table 1: Behavioral parameters registered in the OF test, both 3 and 21 days after treatment. The corresponding $\mathrm{F}$ values of the two-way ANOVA analysis are shown below. $* P<0.05$ compared with saline W21 group or ${ }^{\#} P<0.05$ compared with MDPV W3 group using Bonferroni post hoc test.

\begin{tabular}{|c|c|c|c|c|c|}
\hline Treatment- withdrawal day & Mean speed $(\mathrm{cm} / \mathrm{s})$ & Locomotion (cm) & $\begin{array}{l}\text { Central vs. total } \\
\text { walking ratio }\end{array}$ & $\begin{array}{l}\text { Latency } 1^{\text {st }} \text { entrance } \\
\text { to center (s) }\end{array}$ & Entries in center \\
\hline $\begin{array}{c}\text { Saline W3 } \\
n=7\end{array}$ & $5.57 \pm 0.18$ & $3343.72 \pm 108.06$ & $0.10 \pm 0.014$ & $29.02 \pm 6.19$ & $24.00 \pm 3.09$ \\
\hline $\begin{array}{c}\text { MDPV W3 } \\
n=9\end{array}$ & $5.40 \pm 0.64$ & $3098.83 \pm 338.05$ & $0.17 \pm 0.02$ & $6.72 \pm 2.87$ & $45.87 \pm 8.37$ \\
\hline $\begin{array}{l}\text { Saline W21 } \\
\mathbf{n}=7\end{array}$ & $5.06 \pm 0.29$ & $3035.96 \pm 171.56$ & $0.16 \pm 0.02$ & $35.95 \pm 16.31$ & $35.00 \pm 4.92$ \\
\hline $\begin{array}{l}\text { MDPV W21 } \\
\mathbf{n}=9\end{array}$ & $5.22 \pm 0.76$ & $3360.10 \pm 418.18$ & $0.26 \pm 0.03 * \#$ & $6.13 \pm 2.78^{*}$ & $60.87 \pm 1.74^{\#}$ \\
\hline \multicolumn{6}{|c|}{ Two-way ANOVA analysis } \\
\hline $\begin{array}{c}F \text { (variable treatment (d.f.), } P \text { ) } \\
\text { Paired for } t\end{array}$ & $\begin{array}{c}\mathrm{F}(1,13)=0,0009408 \\
\text { n.s. }\end{array}$ & $\begin{array}{c}\mathrm{F}(1,13)=0,008266 \\
\text { n.s. }\end{array}$ & $\begin{array}{c}\mathrm{F}(1,13)=5,975 \\
P=0.0295\end{array}$ & $\begin{array}{c}\mathrm{F}(1,13)=10.35 \\
P=0.0074\end{array}$ & $\begin{array}{c}\mathrm{F}(1,13)=4.203 \\
P=0.0611\end{array}$ \\
\hline $\begin{array}{c}\text { F (variable time (d.f.), } P \text { ) } \\
\text { Paired for } t\end{array}$ & $\begin{array}{c}\mathrm{F}(1,13)=0,2629 \\
\text { n.s. }\end{array}$ & $\begin{array}{c}\mathrm{F}(1,13)=0,03724 \\
\text { n.s. }\end{array}$ & $\begin{array}{c}\mathrm{F}(1,13)=27,59 \\
P=0.0002\end{array}$ & $\begin{array}{c}\mathrm{F}(1,13)=0,1170 \\
\text { n.s. }\end{array}$ & $\begin{array}{c}\mathrm{F}(1,13)=11.63 \\
P=0.0046\end{array}$ \\
\hline
\end{tabular}

${ }^{*} P<0.05$ vs saline $\mathrm{W} 21 ;{ }^{\#} P<0.05$ vs MDPV W3 
Withdrawal (W)

A
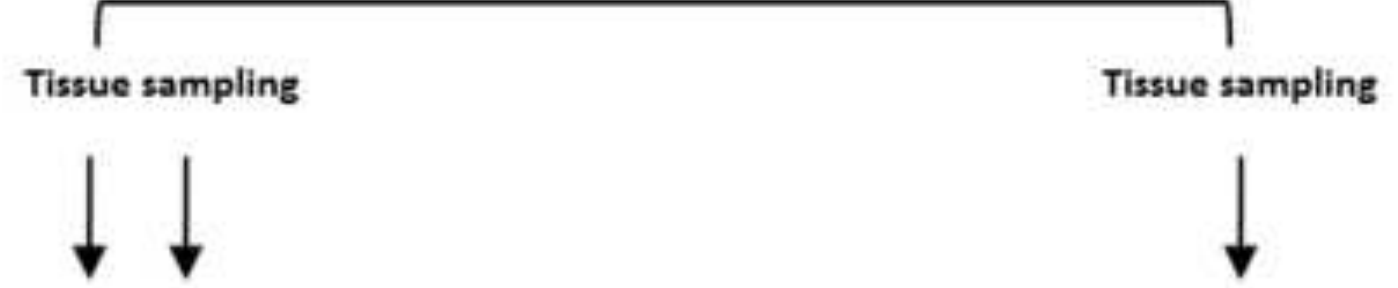

Day: 1
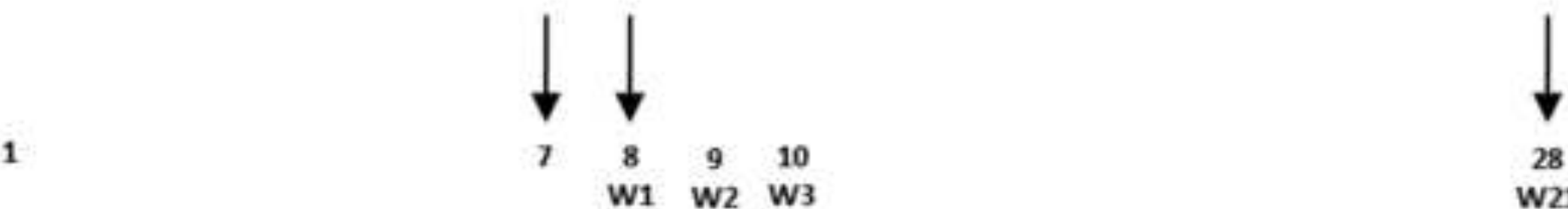

$\begin{array}{ccc}8 & 9 & 10 \\ \text { W1 } & \text { W2 } & \text { W3 }\end{array}$

28
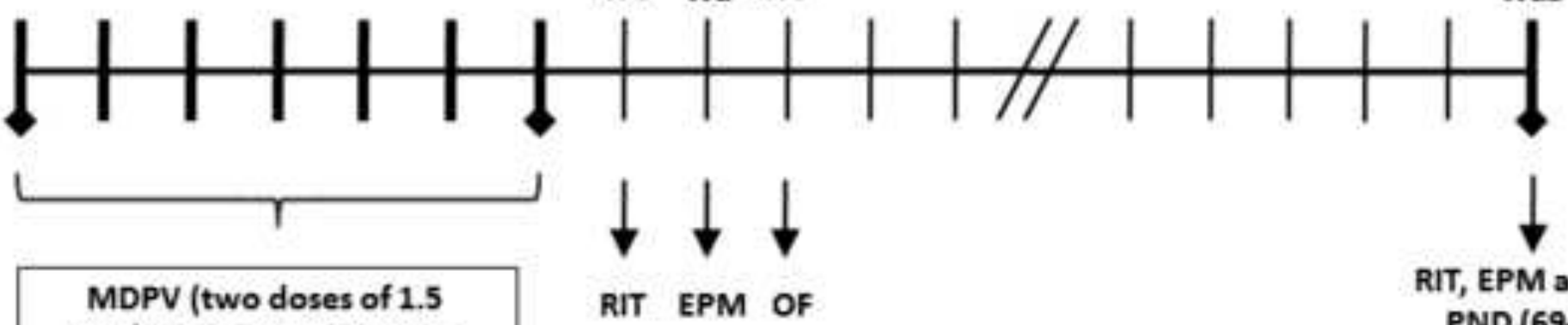

MDPV (two doses of 1.5

$\mathrm{mg} / \mathrm{kg}$ s.c. in one day, $4 \mathrm{~h}$

RIT EPM OF

RIT, EPM and OF

apart) or saline

PND (41-44)

B
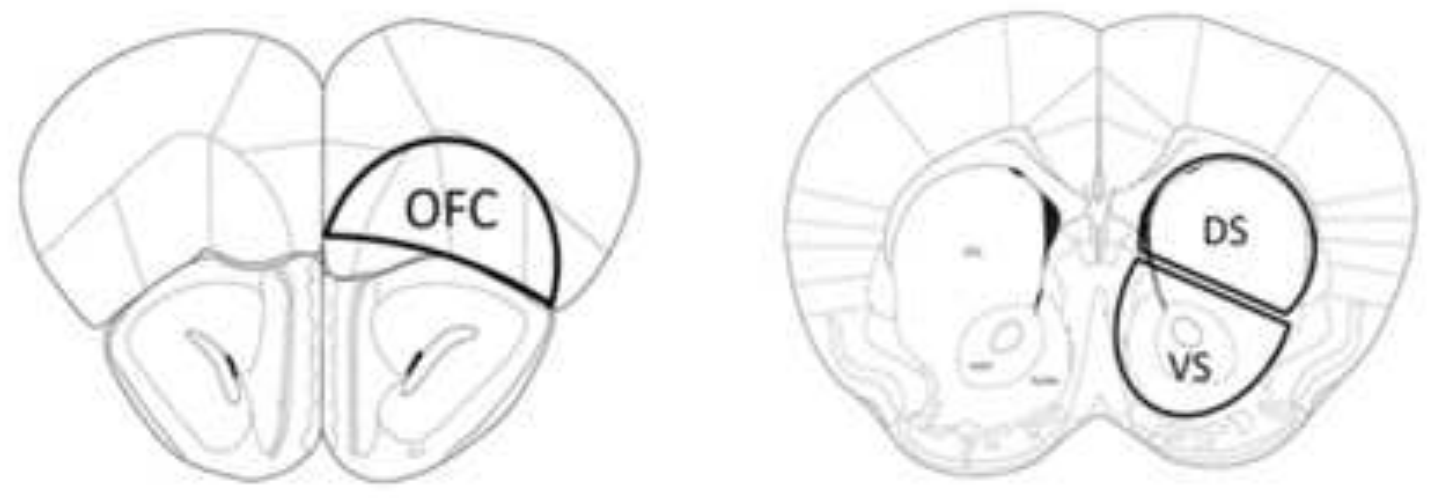

Interaural $6.60 \mathrm{~mm}$

Bregma $2.80 \mathrm{~mm}$ 
A

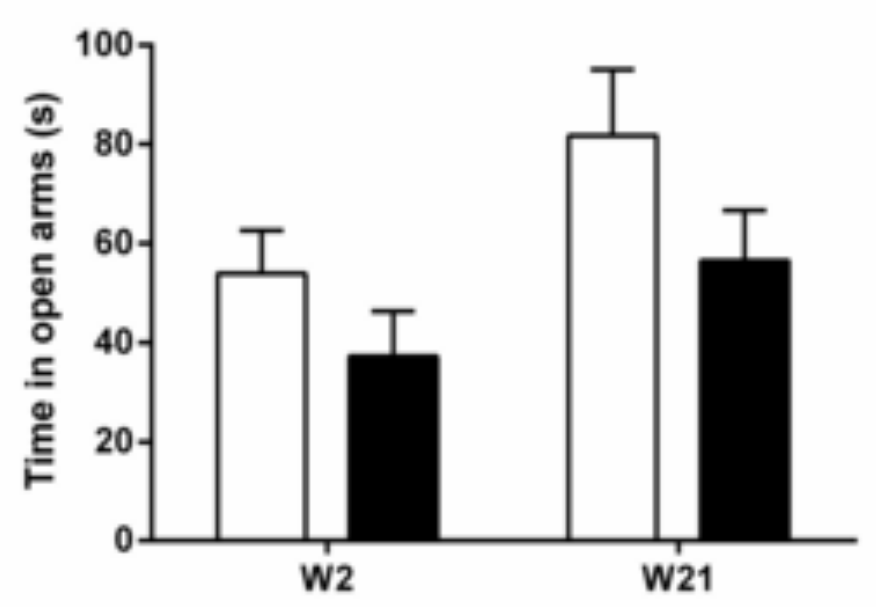

- MDPV

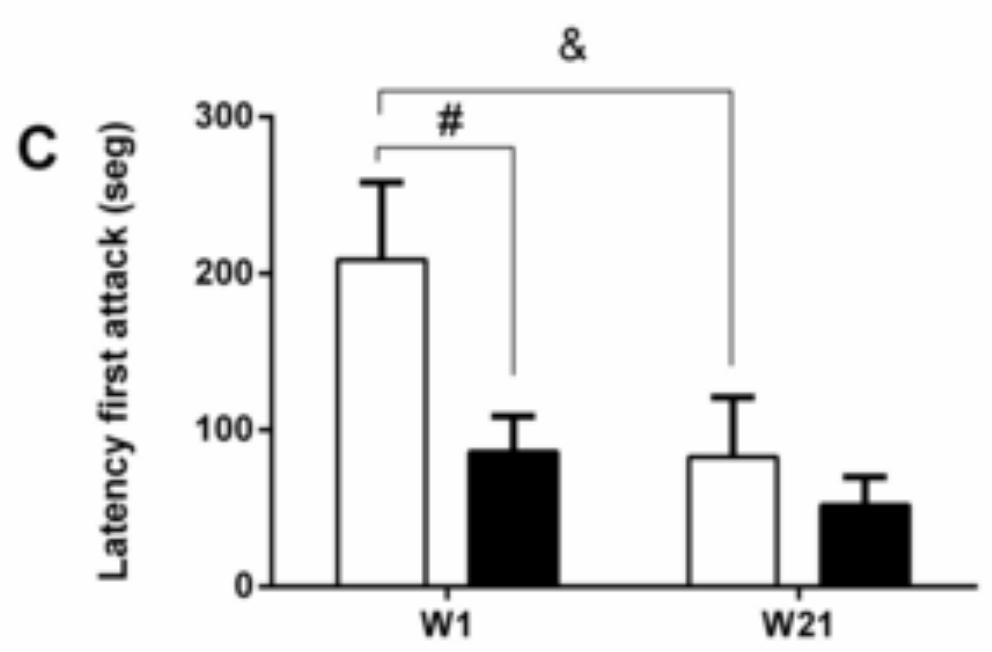

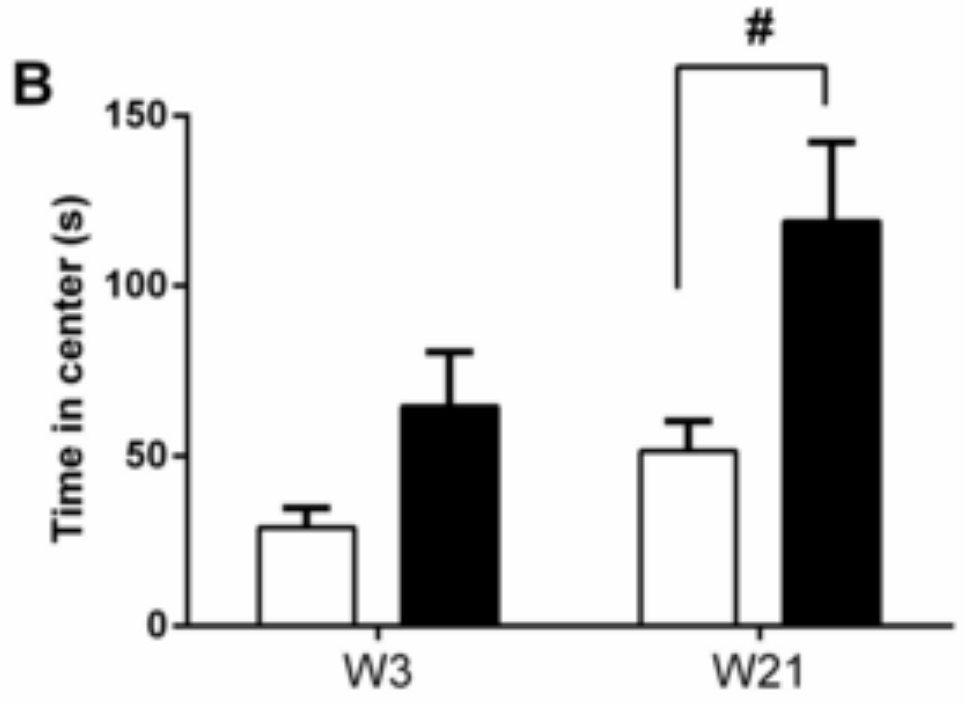

D

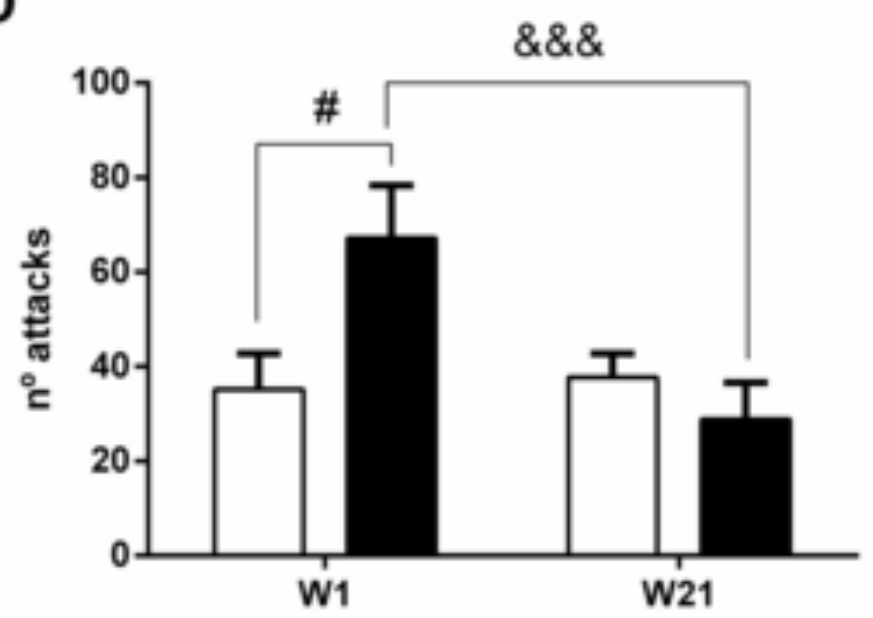


a

W1

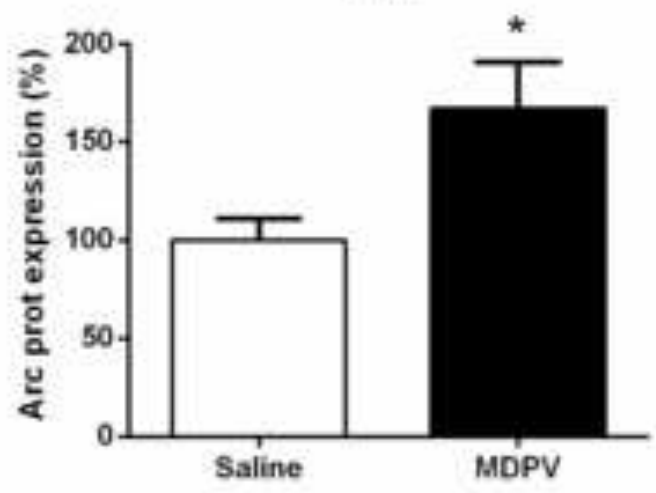

C

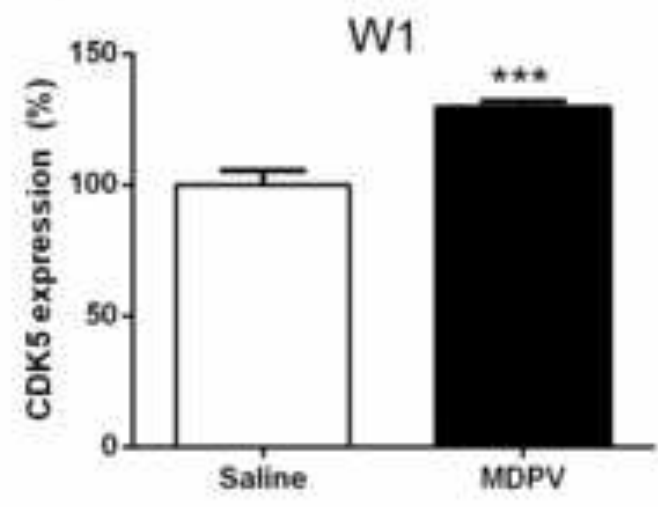

e

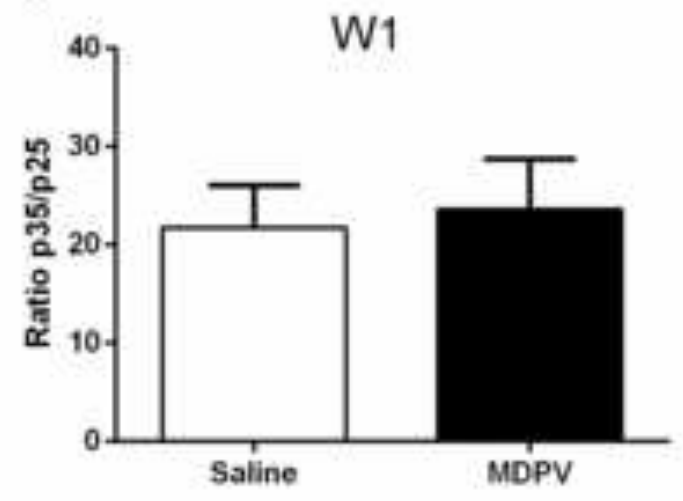

g

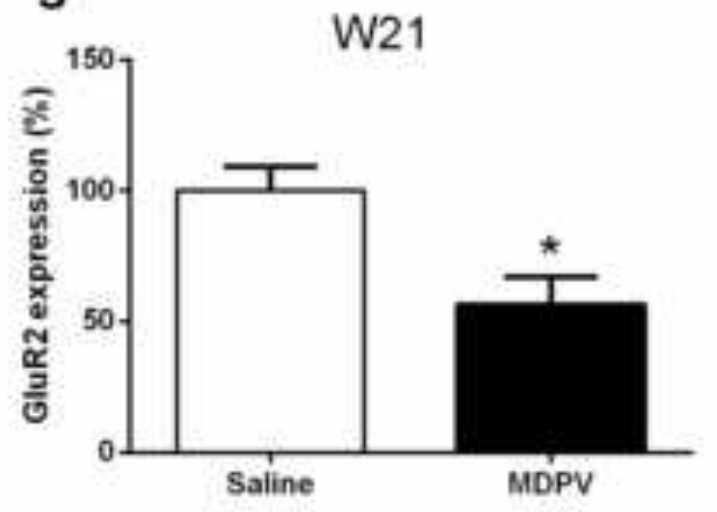

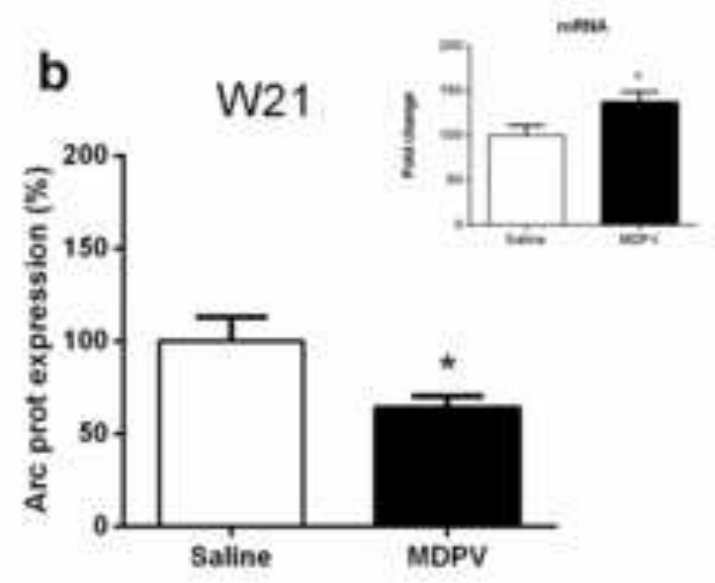

d

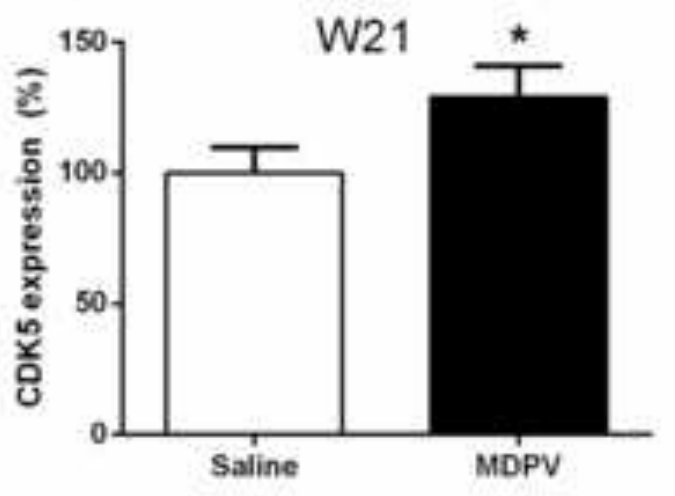

f

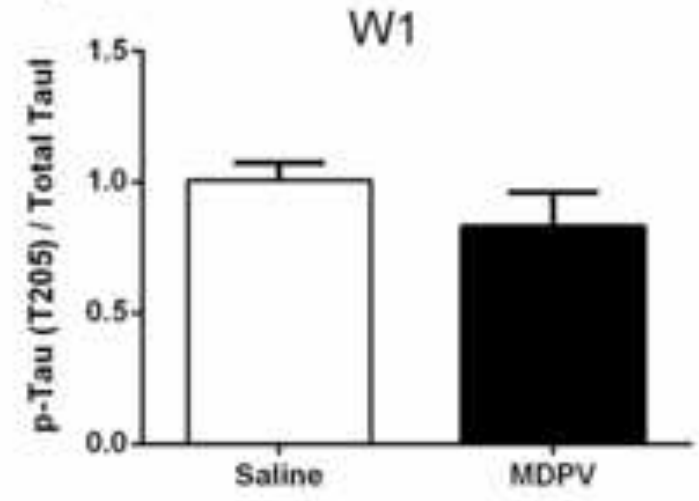

h

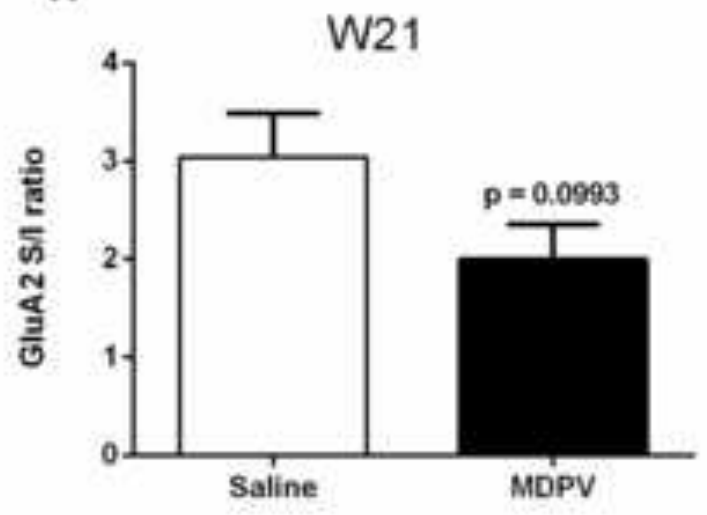




\section{W1}

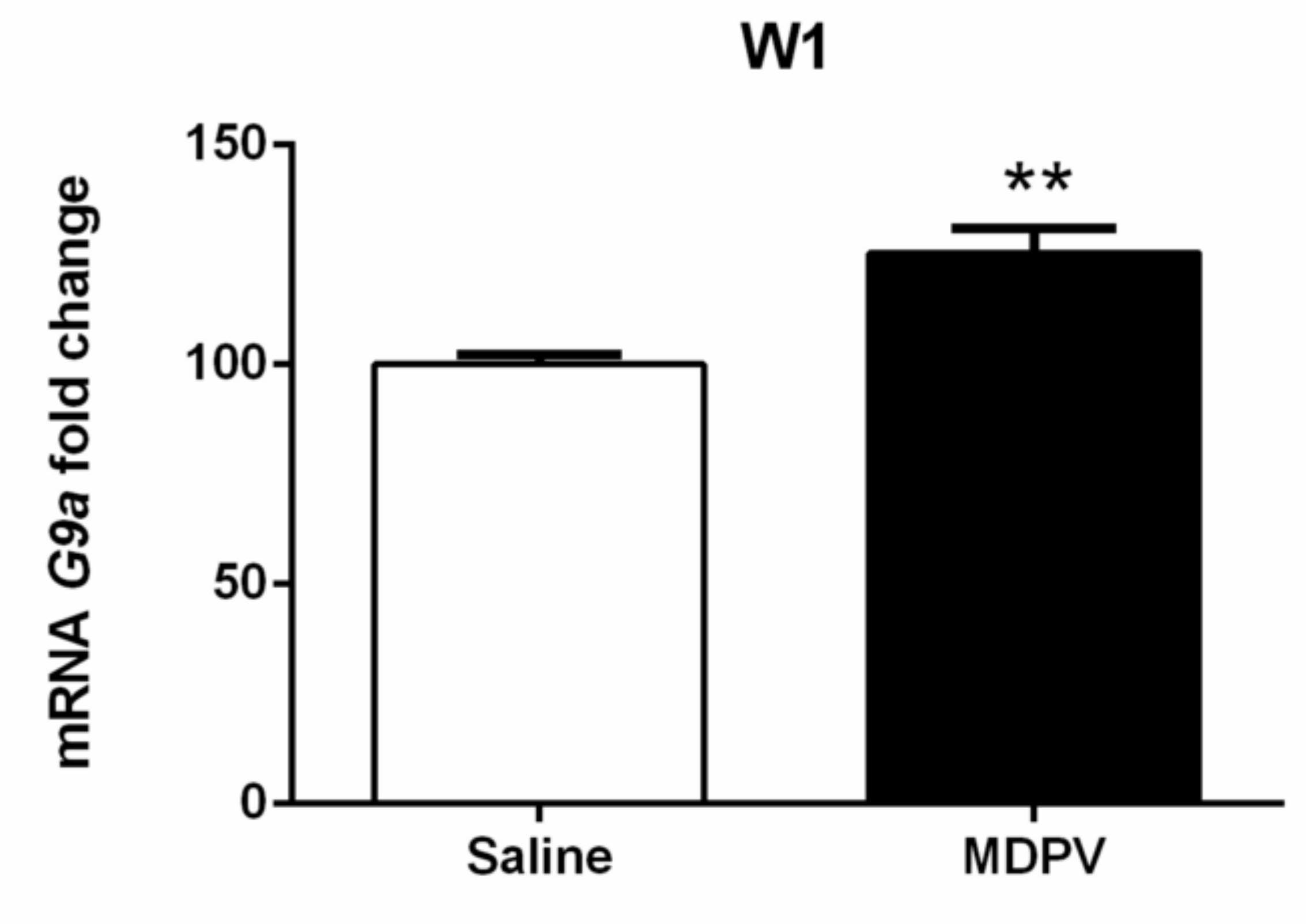

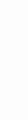

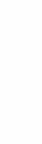


Click here to download high resolution image

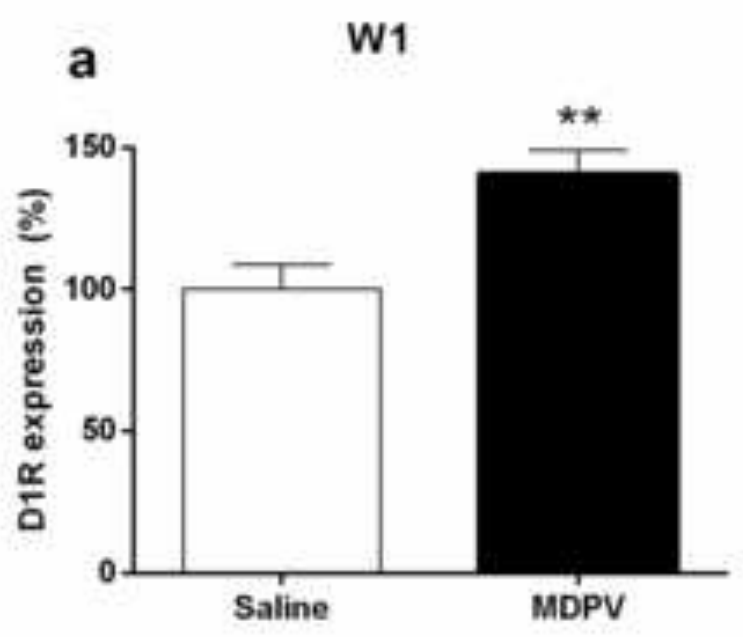

C

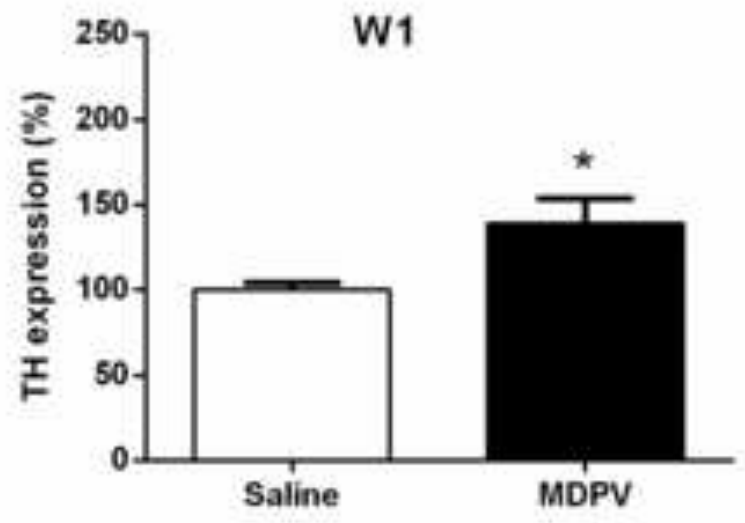

e

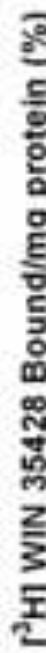

동

W1

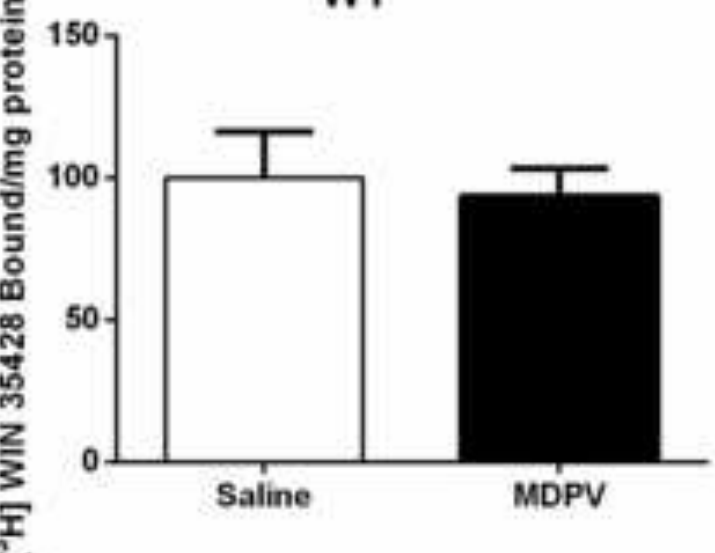

f
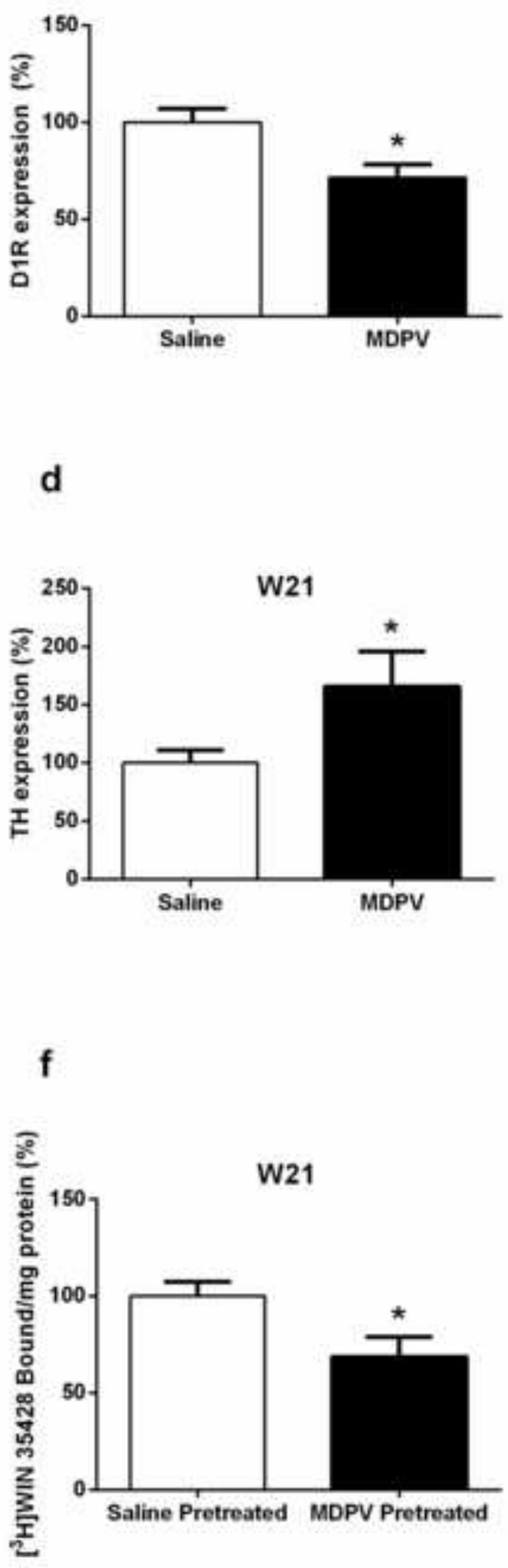

d

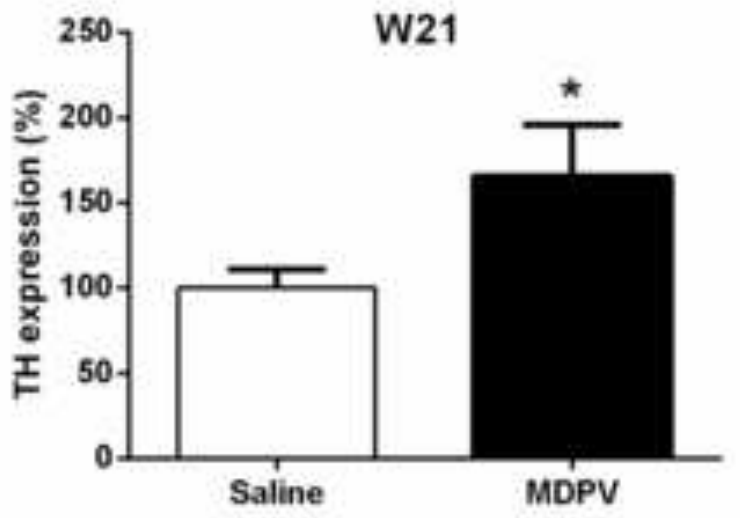




\title{
Click here to download Supplementary Material: Western images.pdf
}

Supplementary Material Western images
Click here to download Supplementary M

\begin{abstract}
Click here to download Supplementary Material: Western images.pdf
\end{abstract}

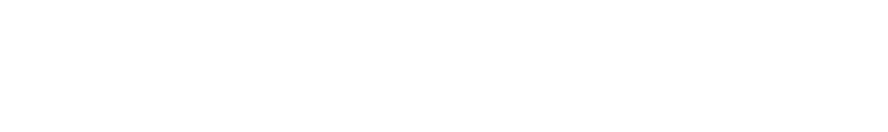
(1) (1) (1) (1) (1) (1) (1) (1) (1) . . . . . . 
Supplementary Material Western
Click here to download Supplementary Material: Westerns.pdf

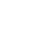

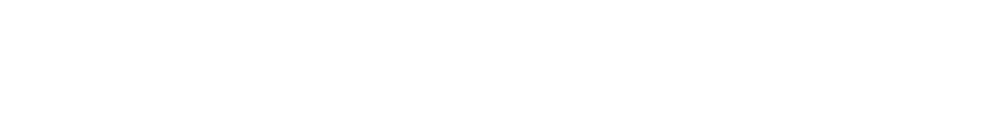

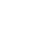

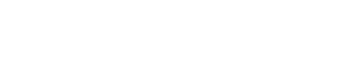
. 列 (1)

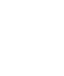

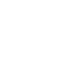

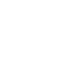

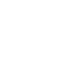
(1)

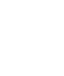

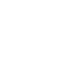

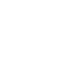
(1) 